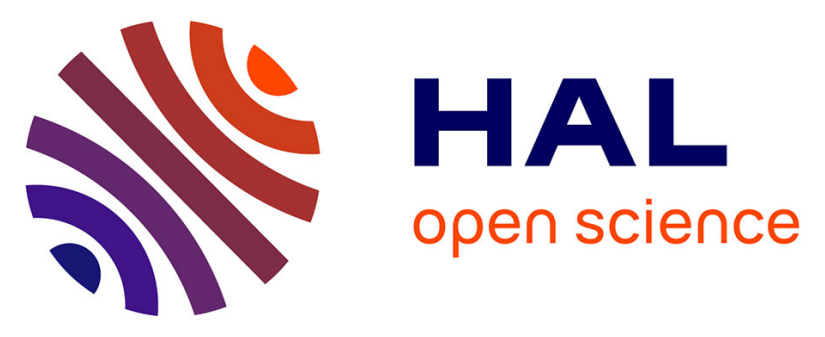

\title{
Energetic properties of rocket propellants evaluated through the computational determination of heats of formation of nitrogen-rich compounds
}

Valérian Forquet, Carles Miro Sabate, Henry Chermette, Guy Jacob, Emilie Labarthe, Henri Delalu, Chaza Darwich

\section{To cite this version:}

Valérian Forquet, Carles Miro Sabate, Henry Chermette, Guy Jacob, Emilie Labarthe, et al.. Energetic properties of rocket propellants evaluated through the computational determination of heats of formation of nitrogen-rich compounds. Chemistry - An Asian Journal, 2016, 11 (5), pp.730-744. 10.1002/asia.201501204 . hal-01363814

\section{HAL Id: hal-01363814 \\ https://hal.science/hal-01363814}

Submitted on 1 Oct 2021

HAL is a multi-disciplinary open access archive for the deposit and dissemination of scientific research documents, whether they are published or not. The documents may come from teaching and research institutions in France or abroad, or from public or private research centers.
L'archive ouverte pluridisciplinaire HAL, est destinée au dépôt et à la diffusion de documents scientifiques de niveau recherche, publiés ou non, émanant des établissements d'enseignement et de recherche français ou étrangers, des laboratoires publics ou privés. 


\title{
Energetic Properties of Rocket Propellants Evaluated through the Computational Determination of Heats of Formation of Nitrogen- Rich Compounds
}

\author{
Valérian Forquet, ${ }^{[a]}$ Carles Miró Sabaté, ${ }^{*[a]}$ Henry Chermette, ${ }^{[b]}$ Guy Jacob, ${ }^{[c]}$ Émilie Labarthe, ${ }^{[d]}$ \\ Henri Delalu, ${ }^{[\mathrm{a}]}$ and Chaza Darwich ${ }^{*[a]}$
}

Abstract: The use of ab initio and DFT methods to calculate the enthalpies of formation of solid ionic compounds is described. The results obtained from the calculations are then compared with those from experimental measurements on nitrogen-rich salts of the 2,2-dimethyltriazanium cation (DMTZ) synthesized in our laboratory and on other nitrogenrich ionic compounds. The importance of calculating accu-

\section{Introduction}

The synthesis of new compounds, in particular, energetic materials, is a time-consuming, costly, and hazardous process that might generate a lot of waste. Therefore, it is only desirable to carry out their synthesis if the target compound has interesting properties. The prediction of physical, chemical, and thermodynamic properties of new materials has become necessary for economic reasons, although the tremendous development of theoretical chemistry has helped this process with the creation of predictive software. However, it is important to remember that such predictions are based on models and approximations. As a consequence, currently available prediction tools describe reality in a simplistic manner and their precision will depend upon the level of theory used and its suitability to the

[a] Dr. V. Forquet, Dr. C. Miró Sabaté, Dr. H. Delalu, Dr. C. Darwich

Université de Lyon, Laboratoire Hydrazines

et Composés Energétiques Polyazotés, UMR 5278

UCBL/CNRS/CNES/Herakles (Safran), 22 avenue Gaston Berger 69622 Villeurbanne (France)

E-mail: carlos.miro-sabate@univ-lyon1.fr chaza.darwich@univ-lyon1.fr

[b] Dr. H. Chermette

Université de Lyon, Institut des Sciences Analytiques

UMR 5280, CNRS, ENS-Lyon, 5 rue de la Doua

69100 Villeurbanne (France)

[c] Dr. G. Jacob

Direction Recherche et Technologie

Herakles (Safran), CRB, 9 rue Lavoisier

91710 Vert-Le-Petit (France)

[d] Dr. É. Labarthe

CNES, Direction des Lanceurs, 52 rue Jacques Hillairet 75012 Paris (France) rate volumes and lattice enthalpies for the determination of heats of formation is also discussed. Furthermore, the crystal structure and hydrogen-bonding networks of the nitroformate salt of the DMTZ cation is described in detail. Lastly, the theoretical heats of formation were used to calculate the specific impulses $\left(l_{\mathrm{sp}}\right)$ of the salts of the DMTZ cation in view of a prospective application in propellant formulations.

problem being investigated. In this regard, it is important to define the precision that can be expected from a given model. For example, for energy calculations, chemical accuracy is achieved when the error is below $1 \mathrm{kcal} \mathrm{mol}^{-1}$. This is in the range of energy involved in van der Waals forces, which are typically considered to be the weakest interactions in chemistry. ${ }^{[1]}$

In the context of energetic materials, it is interesting to predict the performance of such compounds, which is given by detonation parameters (velocity and pressure) for explosive compounds and by the specific impulse in the case of propellants. ${ }^{[2-5]}$ The energy released during the process of decomposition or combustion is one of the key parameters to determine these properties, and can be estimated if the enthalpy of formation $\left(\Delta H_{\mathrm{f}}\right)$ of the compound is known. The other key parameter is the condensed-state density, the prediction of which is not discussed herein. In 1998, it was estimated that for more than 10 million compounds described in the literature, experimental values were available for less than $0.1 \%$ of them, which encouraged the development of prediction software. ${ }^{[6]}$ This development goes from the creation of totally empirical methods (e.g., group contribution) to ab initio calculations through semiempirical and DFT techniques. Although empirical and semiempirical methods require relatively little computer resources and generally allow good results to be obtained, they involve an important amount of parameterization and are generally not suited for atypical compounds (e.g., metastable energetic materials). ${ }^{[7]}$ In addition, although predictions might be satisfactory for compounds similar to those used for parameterization, there is poor extrapolation for species that differ from the parameterized compounds. On the other hand, the use of ab initio and DFT methods to calculate $\Delta H_{\mathrm{f}}$ has grown steadily over the last decade, thanks to advan- 
ces in methodology, improved software, and more powerful computers.

Herein, a brief description of the quantum chemical methods typically used for the calculation of thermochemical data is given. In view of the calculation of gas-phase enthalpies of formation, we first show how formation and atomization reactions, and isodesmic and similar reactions are involved. Then, after a brief review of methods used previously, calculations of the volumes, as well as the determination of the crystal structure of salt 5, are presented. In the following section, we investigate how to calculate ionic volumes and lattice enthalpies, and apply the method to compounds for which no experimental data is available. Next, we discuss how we selected the theory level to calculate the enthalpies of formation. The computed values are then compared with the experimental measurements obtained by means of bomb calorimetry for energetic salts derived from the 2,2-dimethyltriazanium cation (DMTZ; synthesized in our laboratory) and other nitrogen-rich materials (Figure 1). Lastly, we use the calculated heats of formation to estimate the specific impulses $\left(I_{\mathrm{sp}}\right)$ of those salts to evaluate their potential performance in propellant formulations.<smiles>C[N+](C)(N)N</smiles>

1

3

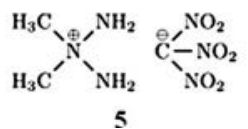

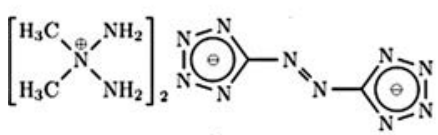

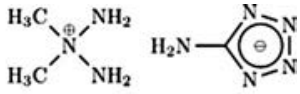

2

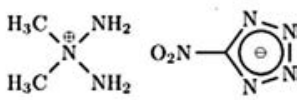

4

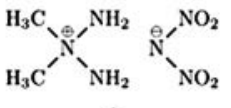

6
Figure 1. Energetic salts based on the DMTZ cation and the azide (1), 5-aminotetrazolate (2), 5,5'-azobistetrazolate (3), 5-nitrotetrazolate (4), nitroformate (5), and dinitramide (6) anions.

\section{Results and Discussion}

\section{Thermochemistry}

One of the most important approximations assumed herein is that all equations apply to noninteracting particles, that is, perfect gases. To calculate the thermochemical properties, we used the Gaussian suite of programs, ${ }^{[8,9]}$ which are based on equations previously described in the literature. ${ }^{[10,11]}$ All frequency calculations include the Gaussian thermochemical analysis, which, by default, is carried out at $298.15 \mathrm{~K}$ and $1 \mathrm{~atm}$ for the major isotope of each element. The difference between the standard pressure ( $1 \mathrm{bar}$ ) and $1 \mathrm{~atm}$ ( $1 \mathrm{bar}=1.01325 \mathrm{~atm}$ ) is neglected for the calculations. Hence, all values herein are considered to be in the standard state.

The global minimum of the potential energy hypersurface corresponds to the electronic energy of the system $\left(E_{\text {elec }}\right)$ in its fundamental state at $0 \mathrm{~K}$. To obtain the true energy of the fundamental state at $0 \mathrm{~K}\left(E_{0}\right)$, one needs to account for the vibra- tional energy of the molecules in that state, so that $E_{0}=E_{\text {elec }}+$ $Z P E$ (ZPE = zero point energy). The calculation of frequencies and ZPE by using the harmonic model leads to systematic errors and an overestimation of the vibrational frequencies for a given level of theory. To compensate for this error (i.e., to take into account anharmonic effects), it is common to use scaling factors, which depend on the method and basis set. The scaling factor tends to one as the basis set grows larger and as more and more electronic correlation is included. The latter statement and the fact that scaling factors are not described for all methods has prompted authors to either use uncorrected values ${ }^{[12]}$ or scaling factors for the same method with different basis sets. For example, Merrill and Gordon calculated ZPEs by using MP2(FC)/aug-cc-pVDZ and applied a correction factor of $0.9646,{ }^{[13]}$ previously determined for MP2(FULL)/6$31 \mathrm{G}(\mathrm{d}){ }_{1}^{[14]}$ which is acceptable because the correction factors have little dependence on the basis set used. ${ }^{[15,16]}$ Notably, however, methods that use virtual orbitals (e.g., MP2) are more sensitive to the choice of basis set than those that do not (e.g., DFT). ${ }^{[16]}$ On the other hand, applying the same scaling factor to high and low frequencies is a crude approximation, ${ }^{[17]}$ although this approach appears to be widespread. In addition, for the same level of theory, the correction factors for the vibrational frequencies and thermochemical properties are different. ${ }^{[14,17,18]}$ Although incorrect, ${ }^{[17]}$ the same scaling factors are sometimes used to correct both frequencies and the ZPE, probably owing to a lack of available literature containing scaling factors for ZPE. Lastly, the correction factor also depends on the size of the molecule, for example, polyatomic molecules will require a smaller correction factor than that of diatomic molecules. ${ }^{[19,20]}$

In practice, authors generally use the Gaussian code and the command "scale" to calculate frequencies. However, for the purpose of this work, we considered it to be more appropriate to a posteriori correct the ZPE values by using scaling factors reported in the literature. In such a way, it will be easier to modify previous results when new scaling factors are published. To consider the corrected values for the ZPE, we used Equation (1) to calculate the enthalpy, $H_{\mathrm{T}}$, from the electronic energy, $E_{\text {elec }}$ (obtained from a single-point calculation), a thermal correction to this enthalpy, and the unscaled ZPE value. For composite methods, the scaling factor is an integral part of the procedure and the enthalpy line can be used directly. Some of the most widely used corrections factors, including those used herein, can be found in the literature. ${ }^{[14-18,20-28]}$

$$
\begin{aligned}
H_{\mathrm{T}}= & E_{\text {elec }}+\text { thermal correction to enthalpy }-\mathrm{ZPE} \\
& \times(1-\text { correction factor })
\end{aligned}
$$

\section{Enthalpies of Formation}

\section{Formation and Atomization Reactions}

There are several ways to calculate the heat of formation of a compound in the gas phase, $\Delta H_{\mathrm{f}}(\mathrm{g}){ }^{[29]}$ The most direct way is to use the -often hypothetical- reaction of formation of the compound from the simplest stable molecules (i.e., $\mathrm{H}_{2}, \mathrm{~N}_{2}, \mathrm{O}_{2}$, 
$\mathrm{C}$ (graphite), etc.). Assuming the condensed phase heat of formation $\left(\Delta H_{\mathrm{f}}(\mathrm{I})\right.$ or $\left.\Delta H_{\mathrm{f}}(\mathrm{s})\right)$ of the target compound is known, this method requires the enthalpies of phase transition which are often unknown for the compound of interest in order to obtain the gas phase heat of formation. However, there are methods to calculate the enthalpies of phase transition from electrostatic potentials. ${ }^{[30-37]}$ A second way to calculate $\Delta H_{\mathrm{f}}(\mathrm{g})$ is to use atomization reactions, in combination with experimental dissociation energies of $\mathrm{H}_{2}, \mathrm{~N}_{2}$, and $\mathrm{O}_{2}$ and the sublimation enthalpy of $\mathrm{C}$ (graphite) for CHNO-based compounds, unless experimental enthalpies of the atoms are available.

The use of either formation or atomization reactions is straightforward; however, the precision of these procedures is strongly dependent on the computational method, mainly because reagents, products, and their electronic correlation energies are very different. Therefore, to obtain satisfactory results from these methods, a high level of theory and powerful computers are needed. ${ }^{[38]}$

\section{Isodesmic and Related Reactions}

The use of highly correlated methods is not always possible, particularly when the compound under consideration is too large. An indirect approach to address this issue is to add the compound of interest in a hypothetical reaction in which reactants and products have similar structures and electronic environments, for example, the same number of electron pairs, the same types of bonds, or similar atom environments. This methodology should cancel out errors, which should be similar for both reagents and products. Consequently, in such a way, a moderate level of theory should be sufficient to afford precise results. To be able to apply this method to determine the heat of formation of a given compound, the heats of formation of all species involved in the reaction need to be known with accuracy. For the purpose of our work, we chose isodesmic reactions, for which there are no changes in the number of electron pairs and the types of bonds between reagents and products. The isodesmic reactions (see below) used for this study are based on the bond separation principle, in which the number of bonds of each type is preserved. As reported by Petersson et al., ${ }^{[39]}$ this method is not suitable for large compounds because numerous small molecules are necessary to complete the isodesmic reaction in such cases and this will multiply errors.

\section{History of Methods Reported in the Literature}

This section summarizes the main methods used to calculate gas-phase enthalpies of formation, which were used in the 2000 s by some prominent authors in the field of energetic materials.

Politzer et al. were some of the first authors to show an interest in the evaluation of energetic compounds by quantum methods. A review published in 2001 summarized their previous work, which described, but was not limited to, the prediction of enthalpies of formation. ${ }^{[40]}$ They used several methods and found that composite methods gave satisfactory results; however, owing to limitations of composite methods for large systems at that time, they turned to less time consuming DFT. Politzer et al. ${ }^{[40]}$ used formation reactions at the B3P86/6-31+ $G(d, p)$ level of theory. However, they found that this procedure tended to underestimate the real heats of formation. They then introduced atomic correction terms, and in 2004 evaluated the heat of formation of nitroacetylene by using its formation reaction and averaging the results obtained from CBS-QB3 and G3(MP2) methods. ${ }^{[41]}$ In $2005,{ }^{[30]}$ the same authors proposed that the B3PW91/6-31G $(\mathrm{d}, \mathrm{p})$ method with atomic corrections was most suited to calculate heats of formation.

In 1999, Rice et al. ${ }^{[31]}$ suggested a method to calculate gasphase heats of formation based on atomic equivalents determined at the B3LYP/6-31G(d) level of theory, with experimental measurements from energetic compounds. Three years later, the same authors used this method to estimate detonation enthalpies by assuming that the latter could be approximated as the difference between the enthalpies of formation of the detonation products and that of the explosive divided by the molar mass of the latter. ${ }^{[42]}$ In 2006, Rice and Byrd calculated new group equivalents and improved their procedure by using the B3LYP/6-311 + +G(2df,2p)//B3LYP/6-31G(d) functional. ${ }^{[32,43]}$ In $2009{ }_{1}^{[44]}$ they calculated heats of formation by using a modified version of the G3(MP2)//B3LYP method ${ }^{[45,46]}$ with B3LYP/6$31+G(d, p)$ instead of B3LYP/6-31G(d) for geometry optimizations.

Since 2006, Shreeve et al. have mainly turned to isodesmic reactions and used MP2/6-311++G(d,p)//B3LYP/6-31+G(d,p) to calculate the enthalpies of formation. ${ }^{[47-50]}$ However, they have also turned to less usual methods, such as G2 or G2MP2, ${ }^{[51-54]}$ or more advanced methods, such as G3 and G3MP2, ${ }^{[53,55]}$ and CBS variants. ${ }^{[53]}$ Typically, these authors use composite methods, especially G2 or G2MP2, for protonation $^{[54,56-64]}$ or atomization ${ }^{[65-71]}$ reactions.

In 2006 and 2007, Klapötke et al. mainly used combustion reactions calculated by using B3LYP/6-31G(d,p) ${ }^{[72]} \mathrm{B} 3 \mathrm{LYP} /$ $\mathrm{SDD}^{[73]}$ B3LYP/cc-pVDZ, ${ }^{[74-76]} \mathrm{MP2} /$ aug-cc-pVDZ, ${ }^{[77-80]}$ and MP2/ cc-pVDZ ${ }^{[12,76,81-85]}$ methods. However, after 2008, they preferred to use atomization reactions calculated by using CBS-4M. ${ }^{[86-88]}$

In 2004, Dixon et al. used atomization reactions and very high levels of theory to calculate the $\Delta H_{\mathrm{f}}(\mathrm{g})$ values of $\mathrm{N}_{3}, \mathrm{~N}_{3}{ }^{-}$, $\mathrm{N}_{5}{ }^{+}$, and $\mathrm{N}_{5}{ }^{-}{ }^{[89]}$ Most geometries were optimized by using $\operatorname{CCSD}(\mathrm{T}) /$ aug-cc-pVTZ or CCSD(T)/aug-cc-pVQZ functionals and the frequencies were determined by using the $\operatorname{CCSD}(T)$ or MP2 methods with an aug-cc-pVDZ basis set.

The calculation methods described above are useful to calculate enthalpies of formation in the gas phase, $\Delta H_{\mathrm{f}}(\mathrm{g})$; however, most of the time, the compounds of interest are either solids or liquids. The $\Delta H_{\mathrm{f}}(\mathrm{g})$ value can easily be transformed into $\Delta H_{\mathrm{f}}(\mathrm{s})$ and $\Delta H_{\mathrm{f}}(\mathrm{l})$ by subtracting the enthalpy of sublimation, $\Delta H_{\text {subr }}$ and the latent enthalpy of vaporization, $\Delta H_{\text {vap }}$ respectively. For ionic compounds of the general formula $\mathrm{M}_{p} \mathrm{X}_{q}$ as in the present case, Equation (2) can be used, which takes into consideration the gas-phase heats of formation of the cation and anion $\left(\Delta H_{\mathrm{f}}\left(\mathrm{M}^{q+}, \mathrm{g}\right)\right.$ and $\Delta H_{\mathrm{f}}\left(\mathrm{X}^{p-}, \mathrm{g}\right)$, respectively) and the lattice enthalpy, $\Delta H_{\mathrm{L}}$. 
$\Delta H_{\mathrm{f}}\left(\mathrm{M}_{p} \mathrm{X}_{q}, \mathrm{~s}\right)=p \Delta H_{\mathrm{f}}\left(\mathrm{M}^{q+}, \mathrm{g}\right)+q \Delta H_{\mathrm{f}}\left(\mathrm{X}^{p-}, \mathrm{g}\right)-\Delta H_{\mathrm{L}}$

Bartlett et al. ${ }^{[90]}$ and Jenkins et al. ${ }^{[91]}$ proposed an empirical Equation [Eq. (3)] to estimate directly the lattice energy of solid ionic compounds, $\Delta U_{\mathrm{L}}\left(\mathrm{M}_{p} \mathrm{X}_{q}, \mathrm{~s}\right)$, up to values of around $5000 \mathrm{~kJ} \mathrm{~mol}^{-1}$. The advantage of this method is that it only needs the volume of the compound. The molecular volumes can be easily deduced from X-ray measurements by dividing the volume of the unit cell by the $Z$ number. The volume of the ionic compound is then considered to be equal to the sum of the volumes of its different ions.

$$
\begin{aligned}
\Delta U_{\mathrm{L}}\left(\mathrm{M}_{p} \mathrm{X}_{q}, \mathrm{~s}\right)= & 2 I\left(\frac{\alpha}{\sqrt[3]{V}}+\beta\right) \\
& =\left(p q^{2}+q p^{2}\right)\left(\frac{\alpha}{\sqrt[3]{V}}+\beta\right)
\end{aligned}
$$

$V=\frac{V_{\text {unitcell }}}{Z}$

Some years later, Jenkins et al. suggested an improvement, Equation (4). ${ }^{[92]}$ Table S1 in the Supporting Information contains the Jenkins' parameters for use in Equations (3) and (4) for ionic compounds with stoichiometries of 1:1. 1:2, 2:1, and 2:2.

$$
\begin{aligned}
& \Delta U_{\mathrm{L}}\left(\mathrm{M}_{p} \mathrm{X}_{q}, \mathrm{~s}\right)=\gamma \sqrt[3]{\frac{\rho}{M_{\mathrm{M}}}}+\delta \\
& \gamma=2 \times 10^{-7} \mid \alpha \sqrt[3]{N_{\mathrm{A}}} \text { and } \Delta=2 \mid \beta
\end{aligned}
$$

The lattice energies calculated from Equations (3) or (4) can both be used to calculate the enthalpies of formation, according to Equation (5), in which $n_{\mathrm{M}}$ and $n_{\mathrm{x}}$ amount to three for monoatomic ions, five for linear polyatomic ions, and six for nonlinear polyatomic ions, for the cation and anion, respectively.

$\Delta H_{\mathrm{f}}\left(\mathrm{M}_{p} \mathrm{X}_{q}, \mathrm{~s}\right)=\Delta U_{\mathrm{L}}+\left[p\left(\frac{n_{\mathrm{M}}}{2}-2\right)+q\left(\frac{n_{\mathrm{X}}}{2}-2\right)\right] R T$

Although these equations were initially designed for inorganic ionic compounds, they were quickly adopted for the study of systems as diverse as haloorganostannates(IV) ${ }^{[93]}$ hydrogen bonding ${ }_{i}^{[94]}$ high energy density materials (HEDMs) ${ }_{i}^{[95]}$ and polynitrogen compounds, such as $\mathrm{N}_{5}{ }^{+}{ }^{\left[{ }^{[6]}\right.}$ Later, Gutowski et al. suggested new $\alpha$ and $\beta$ coefficients from the study of 23 organic nitrogen-based salts with a 1:1 stoichiometry. ${ }^{[97]} \mathrm{Al}-$ though the use of these new parameters reduced the error on calculated lattice enthalpies, the calculated heats of formation of imidazolium, 1,2,4-triazolium, and tetrazolium salts studied differed substantially from the experimental values. The analysis of these results prompted Gutowski et al. to consider that many of the experimental heats of formation reported in the literature might be questionable. ${ }^{[97]}$

More recently, Rice and Byrd compared several methods for the prediction of solid-phase enthalpies of formation of energetic salts. ${ }^{[44]}$ All lattice enthalpies were determined according to Equation (5), but the lattice energies were calculated by using different methods.
The results that showed the best agreement with the experimental values were obtained for 1:1-type salts, the enthalpies of formation of which in the gas phase were calculated by using the composite method G3(MP2)//B3LYP, ${ }^{[45,46]}$ and the lattice enthalpies were determined with the coefficients reported by Gutowski et al. ${ }^{[97]}$ These results suggest that it would be desirable to determine new coefficients for salts with other stoichiometries.

\section{Calculation of Volumes}

For ionic species, it is necessary to optimize the anion and cation separately. Generally, the volumes of the ions are considered to be additive according to Equation (6):

$V\left(\mathrm{M}_{p} \mathrm{X}_{q}\right)=p V\left(\mathrm{M}^{q+}\right)+q V\left(\mathrm{X}^{p-}\right)$

Marcus et al. compared ionic volumes of anions and cations calculated by using different procedures and showed there was a linear correlation between their results. ${ }^{[98]}$ Their approach considered the ions as spheres and calculated the volume from the ionic radius. Notably, this approximation was based on the assumption that ions had perfectly spherical geometry and overestimated the volume of nonspherical ions.

As a prediction tool, which did not require any experimental data, Jenkins et al. introduced what they called the isomagnetic rule, which stated that salts with the same chemical formula and same charges had approximately the same formula unit volumes. ${ }^{[99]}$ However, this approach is somewhat arbitrary and requires a volume database. For these reasons, we did not use the above approaches herein.

Another method, which also does not require any experimental data and is implemented in the Gaussian software, that appears to be less arbitrary and of broader scope (it is not ion dependent) is based on the calculation of the volume inside the 0.001 a.u. isosurface of the electron density. Qiu and coworkers showed there was a good agreement for nitraminebased compounds when comparing the experimental densities with those calculated by using predicted volumes at the B3LYP/6-31G(d,p) level of theory. ${ }^{[100]}$ They found that larger basis sets gave larger volumes (lower densities) than those of the experimental values. This was in contrast with results reported by Jenkins et al. ${ }^{\left[{ }^{[99]}\right.}$ who found that volumes calculated at the B3LYP/LANL2DZpd level were systematically lower than those of the experimental values. This disagreement in the literature was solved by the work of Rice and co-workers, ${ }^{[101]}$ who found a good agreement between experimental volumes of different CHNO-based compounds, including nitrogen-rich and energetic salts, and those calculated at the B3LYP/6$31 \mathrm{G}(\mathrm{d}, \mathrm{p})$ level of theory. Consequently, the latter approach was preferred whenever experimental volumes were not available.

\section{Crystal Structure of Salt 5}

Salt 5 was obtained by the metathesis reaction of 2,2-dimethyltriazanium sulfate ${ }^{[102]}$ with barium nitroformate. Single crystals 
of the compound were obtained by recrystallization from isopropanol and cooling at $-20^{\circ} \mathrm{C}$ overnight.

The crystal structure of the nitroformate salt is described herein as a representative example of a DMTZ salt. Tables S4S6 in the Supporting Information contain the crystal structure solution and refinement data, selected bond lengths and angles, and the geometry of the hydrogen bonds for this compound, respectively. The asymmetric unit of $\mathbf{5}$ is made up of two crystallographically independent cations and anions (Figure 2). Two of the nitro groups in the anion are approxi-

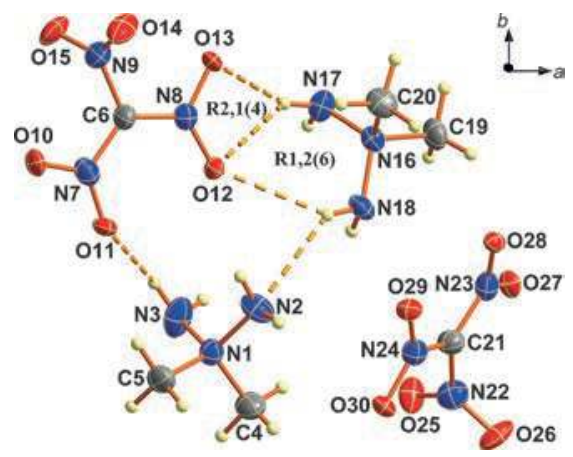

Figure 2. Asymmetric unit cell of $\mathbf{5}$ with the labeling scheme used herein (ellipsoids are drawn at the $50 \%$ probability level).

mately coplanar with the $\mathrm{CN}_{3}$ plane, whereas the third group is approximately perpendicular. The bond lengths and angles in the anion are, within the margins of error, comparable to those of metal and nitrogen-rich salts of the nitroformate anion. ${ }^{[77,103]}$

Salt $\mathbf{5}$ is involved in extensive hydrogen bonding and forms a total of 10 classical and 4 nonclassical hydrogen bonds (Table 56 in the Supporting Information). Figure 3 shows the packing around one of the two crystallographically independent anions in the structure of compound 5. Two of the nitro groups are involved in hydrogen bonding to three cations, whereas the oxygen atoms of the third nitro group interact with the protons of the methyl groups below $3.0 \AA$. The 10 classical hydrogen bonds summarized in Table S6 in the Sup-

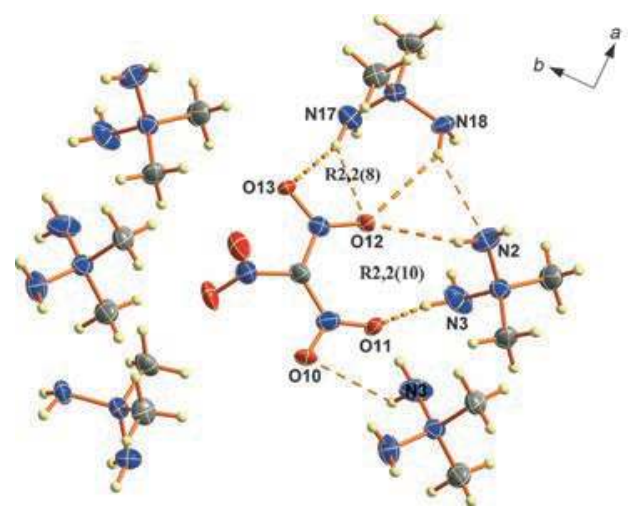

Figure 3. Packing around one of the anions in the crystal structure of $\mathbf{5}$. porting Information are involved in the formation of dimeric patterns at the primary level. These interactions combine at the secondary level to form dimeric interactions ${ }^{[104]}$ of the type $\mathrm{D} 1,2(3), \mathrm{D} 2,1(3)$, and $\mathrm{D} 2,2(X)(X=4-7)$; chain graph sets with the descriptors $C 2,2(X)(X=6,10)$; and ring patterns with the labels $\mathrm{R} 1,2(6), \mathrm{R} 2,1(4)$, and $\mathrm{R} 2,2(X)(X=8,10)$. These ring graph sets are represented in Figures 2 and 3. For example, one of the amino groups forms two hydrogen bonds to the same nitro group $(\mathrm{N} 17 \cdots \mathrm{O} 12=2.5200$ and $\mathrm{N} 17 \cdots 013=2.4350 \AA)$, which yields $\mathrm{R} 2,1(4)$ graph sets, or the interaction between two amino groups of one cation and two nitro groups of one anion ( $\mathrm{N} 2 \cdots \mathrm{O} 12=2.3930$ and $\mathrm{N} 3 \cdots \mathrm{O} 11=2.5070 \AA \AA$ ) form $\mathrm{R} 2,2(10)$ networks.

\section{Ionic Volumes and Lattice Enthalpies}

For nearly all compounds described herein (1-5; Figure 1), we measured the volumes by means of X-ray crystallography at room temperature and used these values to calculate the lattice energy and lattice enthalpy by using Equations (3) and (5).

Table S2 in the Supporting Information contains the values obtained by using the $\alpha$ and $\beta$ coefficients suggested by Jenkins et al. ${ }^{\left[{ }^{[1]}\right.}$ and Table S3 in the Supporting Information shows the values obtained by using the $\alpha$ and $\beta$ coefficients suggested by Gutowski et al. ${ }^{[97]}$ for 1:1 salts (i.e., all salts discussed herein, except 3). The lattice enthalpies obtained by using the Gutowski coefficients are in the range of around $20 \mathrm{kcal} \mathrm{mol}^{-1}$ higher than those obtained by using the Jenkins coefficients.

If possible, it is preferable to use experimental volumes (from X-ray experiments, see above) obtained at room temperature rather than calculated values. However, as mentioned above, experimental data is not always available. Difficulties in obtaining single crystals of the dinitramide salt 6 to obtain the volume of the compound prompted us to study a method that would allow us to predict volumes for salts of the DMTZ cation. Hence, we calculated the volumes of the DMTZ cation and of the different anions in this study separately, and used Equation (6) to obtain volumes of the different salts. In all cases, we used the volume from an isodensity surface polarized continuum model (IPCM) calculation with the B3LYP functional (see the Supporting Information for technical details). Based on available literature, we selected the following three basis sets for our calculations to determine the corresponding volumes (abbreviated as $V_{6-31 G(d, p)}, V_{6-31+G(d),}$ and $V_{\text {TZVP }}$ ): 6$31 \mathrm{G}(\mathrm{d}, \mathrm{p}), 6-31+\mathrm{G}(\mathrm{d})$, and TZVP. In addition, we also used corrections proposed by the groups of Rice ${ }^{[101]}$ and Gutowski ${ }^{[97]}$ to obtain the corrected volumes [Eqs. (7) and (8), respectively], which were then compared with the experimental values obtained from the crystallographic measurements (Table 1).

$$
\begin{aligned}
& V_{6-31 G(\mathrm{~d}, \mathrm{p}), \text { corrRice }}=V_{6-31 \mathrm{G}(\mathrm{d}, \mathrm{p})}-(0.6763+0.9418 \times n H) \\
& V_{\text {TZVP, corrGutowski }}=1.03 \times V_{\text {TZVP }}-0.03
\end{aligned}
$$

For each of the prediction methods used, we calculated the square root of the mean standard deviation (RMSD) to decide which method gave the best results. The volumes calculated 
Table 1. Calculated volumes of the DMTZ salts described herein and a comparison with the experimental values $\left(V_{\text {expt }}\right)$ obtained from X-ray measurements at room temperature.

\begin{tabular}{|c|c|c|c|}
\hline Salt & $V$ considered & Calcd $V\left[\AA^{3}\right]$ & $V_{\text {calcd }}-V_{\text {exptl }}\left[\AA^{3}\right]$ \\
\hline \multirow{6}{*}{1} & $V_{\text {exptl }}$ & 151.4 & \\
\hline & $V_{6-31 G(d, p)}$ & 164.1 & 12.7 \\
\hline & $V_{6-31+G(d)}$ & 173.7 & 22.3 \\
\hline & $V_{\text {TZVP }}$ & 170.2 & 18.8 \\
\hline & $V_{6-31 G(\mathrm{~d}, \mathrm{p}), \text { corrRice }}$ & 154.0 & 2.6 \\
\hline & $V_{\text {TZVP,corrGutowski }}$ & 175.3 & 23.9 \\
\hline \multirow{6}{*}{2} & $V_{\text {exptl }}$ & 200.1 & \\
\hline & $V_{6-31 G(d, p)}$ & 205.7 & 5.6 \\
\hline & $V_{6-31+G(d)}$ & 216.4 & 16.3 \\
\hline & $V_{\text {TZVP }}$ & 213.2 & 13.1 \\
\hline & $V_{6-31 G(\mathrm{~d}, \mathrm{p}), \text { corrRice }}$ & 193.7 & -6.4 \\
\hline & $V_{\text {TZVP,corrGutowski }}$ & 219.6 & 19.5 \\
\hline \multirow{6}{*}{3} & $V_{\text {exptl }}$ & 381.5 & \\
\hline & $V_{6-31 G(d, p)}$ & 389.6 & 8.1 \\
\hline & $V_{6-31+G(d)}$ & 409.5 & 28.0 \\
\hline & $V_{\text {TZVP }}$ & 402.8 & 21.3 \\
\hline & $V_{6-31 G(d, p), \text { corrRice }}$ & 379.5 & -2.0 \\
\hline & $V_{\text {TZVP,corrGutowski }}$ & 414.8 & 33.3 \\
\hline \multirow{6}{*}{4} & $V_{\text {exptl }}$ & 221.8 & \\
\hline & $V_{6-31 G(d, p)}$ & 221.1 & -0.7 \\
\hline & $V_{6-31+G(d)}$ & 232.0 & 10.2 \\
\hline & $V_{\text {TZVP }}$ & 228.2 & 6.4 \\
\hline & $V_{6-31 G(d, p), \text { corrRice }}$ & 211.0 & -10.8 \\
\hline & $V_{\text {TZVP,corrGutowski }}$ & 235.0 & 13.2 \\
\hline \multirow{6}{*}{5} & $V_{\text {exptl }}$ & 242.1 & \\
\hline & $V_{6-31 G(d, p)}$ & 238.9 & -3.2 \\
\hline & $V_{6-31+G(d)}$ & 250.9 & 8.8 \\
\hline & $V_{\text {TZVP }}$ & 247.9 & 5.8 \\
\hline & $V_{6-31 G(\mathrm{~d}, \mathrm{p}), \text { corrRice }}$ & 228.8 & -13.3 \\
\hline & $V_{\text {TZVP,corrGutowski }}$ & 255.3 & 13.2 \\
\hline
\end{tabular}

with B3LYP/6-31G $(d, p)$ appeared to give the best agreement with the experimental values $\left(\mathrm{RMSD}=7.3 \AA^{3}\right)$. Generally speaking, the volumes obtained with the $6-31 \mathrm{G}(\mathrm{d}, \mathrm{p})$ basis set were larger than the experimental values. On the other hand, the volumes obtained with the Rice correction tended to underestimate the experimental values. The remainder of the methods evaluated herein tended to systematically overestimate the volumes relative to the experimental values.

After identifying the most precise method to calculate volumes (B3LYP/6-31G(d,p)), we applied it to the dinitramide salt 6 for which we could not obtain experimental data. The volume of compound 6 under room-temperature conditions was predicted to be $203 \AA^{3}$. With this value, we calculated a standard lattice enthalpy of $508.0 \mathrm{~kJ} \mathrm{~mol}^{-1}\left(121.4 \mathrm{kcal} \mathrm{mol}^{-1}\right)$ by using the coefficients of Jenkins ${ }^{[91]}$ and $603.0 \mathrm{~kJ} \mathrm{~mol}^{-1}$ $\left(144.1 \mathrm{kcal} \mathrm{mol}^{-1}\right)$ by using those of Gutowski. ${ }^{[97]}$

\section{Selection of the Theory Levels}

Given the many possible combinations of methods and basis sets available, it is of primary importance to select an appropriate model in accordance with the system to be studied and the available resources. Herein, we used several levels of theory and compared them with experimental results to find the most suitable method for predicting the properties of the nitrogen-rich compounds under study. It was clear to us that, owing to the lack of Coulomb correlation, HF theory ${ }^{[38]}$ would not be suitable for our system because it would not give an accurate energy value compared with other methods. For geometry optimizations and calculations of the vibrational frequencies, the DFT and MP2 methods are most commonly used because they include electron correlation and are relatively fast. In particular, DFT is faster than MP2 (calculation time is proportional to $N^{3} \sim N^{4}$ versus proportional to $N^{5}$ ) and are often at least as accurate for the geometries of CHNO compounds, ${ }^{[19,105]}$ especially when using a hybrid functional containing Becke's B3 exchange, such as B3LYP or B3PW91. ${ }^{[18,26]}$ Other highly correlated methods, such as MP4, Cl, CC, and QCl, are to be avoided for geometry optimization owing to their long calculation times, and because they do not provide significantly better geometries than other methods at a lower level of theory. Notably, these methods are generally used for single-point calculations on optimized geometries (at a lower level of theory) and $\operatorname{CCSD}(T)$, in particular, is often considered as a reference for the evaluation of other (lower-level) methods.

In addition to the method, the basis set also ought to be chosen carefully. For polynitrogen-based compounds, Kwon and McKee recommended the use of (at least) triple- $\zeta$ basis sets, such as $6-311+\mathrm{G}(\mathrm{d}) .{ }^{[106]}$ In addition, it is essential to use polarization functions, particularly to obtain correct vibrational frequencies. According to Anderson and Uvdal, ${ }^{[15]}$ at least $(2 d, p)$ polarization functions are necessary for hydrazine, from which the DMTZ cation is derived. This level of polarization was thus considered as the minimum acceptable for this work. To calculate the anionic part of the salts described herein, the use of diffuse functions was necessary. Therefore, we also used diffuse functions to calculate the cations to combine coherently the results of anions and cations.

In addition to the methods stated above, we also considered composite methods for our calculations. These methods aim to approach results obtained from a very high level calculation by using corrective terms for a relatively short calculation time. For example, a calculation with G2(B3LYP/MP2/CC) is faster and will give more accurate values than a calculation with B3LYP/6-311+G(3df,2p). ${ }^{[107]}$ Contrary to $G n$ methods, CBS methods are size-consistent and, when comparing methods of the same generation, CBS methods are significantly faster than $\mathrm{Gn}$ methods. The cheapest CBS method in terms of calculation time is CBS-4M, which optimizes the geometry and calculates the ZPE at the UHF/3-21G(d) level of theory. ${ }^{[108]}$ However, this method is not suitable for the purposes of this study, as discussed above. On the other hand, the CBS-QB3 method optimizes the geometry and calculates the ZPE at the B3LYP/6$311 \mathrm{G}(2 \mathrm{~d}, \mathrm{~d}, \mathrm{p})$ level of theory, which is adapted to the systems in this study. ${ }^{[109]}$ Unfortunately, none of the Gn and CBS methods available in the Gaussian software use diffuse functions for geometry optimization and frequency calculations. In this context, Brinck and Rahm developed the G2X method by including diffuse functions into the $\mathrm{G} 2$ method. ${ }^{[110]}$ Based on the defi- 
ciencies and virtues of the methods described above, we considered the following five methods to be the most suited for our systems: 1) B3LYP/6-311 $+\mathrm{G}(2 \mathrm{~d}, \mathrm{p})$ with a scaling factor of 0.9877 for the $Z P E_{1}^{[15]}$ 2) B3LYP/6-311+ $+\mathrm{G}(3 \mathrm{df}, 3 \mathrm{pd}) / / \mathrm{B} 3 \mathrm{LYP} / 6$ $311+G(2 d, p), \quad 3)$ B3LYP/aug-cc-pVTZ//B3LYP/6-311 + G(2d,p), 4) $\operatorname{CCSD}(T) /$ aug-cc-pVTZ//B3LYP/6-311 + G(2d,p), and 5) CBSQB3.

\section{Calculation of Enthalpies of Formation}

The relatively small size of the compounds used in this study coupled with the available computer resources allowed us to use highly correlated methods. Therefore, atomization and formation reactions could be used in this work and should both lead to accurate results. However, isodesmic reactions are still attractive owing to their inherent properties of compensating for errors regardless of the method used, if precise experimental values are available. The two main databases used for this work were the NIST WebBook of Chemistry ${ }^{[111]}$ and the Handbook of Chemistry and Physics. ${ }^{[112]}$

\section{DMTZ Cation}

We calculated the enthalpy of each species involved in the reactions shown in Equations (9) and (10) separately to determine the enthalpy of the isodesmic reactions [see Eq. (11)]. This allowed us to determine the enthalpy of the reaction and, by using the gas-phase enthalpies of formation of the species, the enthalpy of formation of the DMTZ cation can be calculated by using the reaction depicted in Equation (9) in combination with Equation (12).

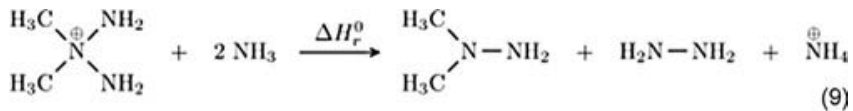

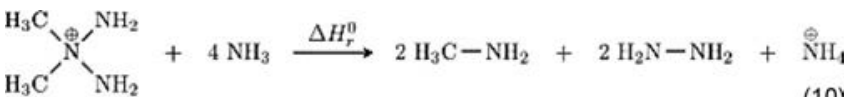

$$
\left.\left.\Delta H_{\mathrm{r}}{ }^{0}=\Sigma H^{0} \text { (products }\right)-\Sigma H^{0} \text { (reactants }\right)
$$

$$
\begin{aligned}
\Delta H_{\mathrm{f}}{ }^{0}\left(\mathrm{DMTZ}^{+}\right)= & \Delta H_{\mathrm{f} \text { exptl }}{ }^{0}(\mathrm{UDMH})+\Delta H_{\mathrm{f} \text { exptl }}{ }^{0}\left(\mathrm{~N}_{2} \mathrm{H}_{4}\right) \\
& +\Delta H_{\mathrm{f} \text { exptl }}{ }^{0}\left(\mathrm{NH}_{4}{ }^{+}\right)-\Delta H_{\mathrm{r}, \text { calcd }}{ }^{0}-2 \times \Delta H_{\mathrm{f}, \text { exptl }}{ }^{0}\left(\mathrm{NH}_{3}\right)
\end{aligned}
$$

Table 2 contains the gas-phase enthalpies of formation of the DMTZ cation calculated by using the different methods introduced above and Equations (9) and (10). To give the reader an idea of the calculation time required for each method, this is given by the central processing unit (CPU) time divided by the number of cores used (i.e., 12, see the Experimental Section).

Knowing that calculations with the $\operatorname{CCSD}(\mathrm{T})$ method generally lead to more precise values $\left[\Delta H_{\mathrm{f}}(\mathrm{DMTZ})=765.5 \mathrm{~kJ} \mathrm{~mol}^{-1}\right.$; Eq. (9)], we found that the B3LYP method overestimated the heat of formation of the DMTZ cation by $20-25 \mathrm{~kJ} \mathrm{~mol}^{-1}$ when using Equation (9) and gave a value of around $40 \mathrm{~kJ} \mathrm{~mol}^{-1}$ when using Equation (10). Notably, the smaller disagreement between the values obtained with Equation (9) is in keeping with the preference for Equation (9) over that of Equation (10), as mentioned above. Therefore, hereafter, only Equation (9) was used for the calculations presented below. However, in the case of highly correlated methods, such as $\operatorname{CCSD}(T)$ and CBSQB3, there is little difference between the values obtained with either Equations (9) or (10) (around $5 \mathrm{~kJ} \mathrm{~mol}^{-1}$ ). Nevertheless, the values calculated were well below that reported by Shreeve et al. ${ }^{[54]}\left(\Delta H_{\mathrm{f}}(\mathrm{DMTZ})=1197 \mathrm{~kJ} \mathrm{~mol}^{-1}\right)$ obtained by using the G2 composite method with Equation (10). These authors, however, did not describe performing experimental tests to prove their claim.

To avoid errors related to the arbitrary choice of an isodesmic reaction [e.g., Eq. (9) over Eq. (10)] and related to possible experimental errors, atomization reactions offer an excellent and unequivocal alternative. Atomization reactions offer the advantage of being unique for each compound and the only necessary experimental values used to calculate the heats of reactions are those concerning the individual atoms for which very precise values can be found in the literature. On the downside, in atomization reactions, the errors are not compensated for in both sides of the equations, as they would be for isodesmic reactions, and therefore, highly correlated methods, such as $\operatorname{CCSD}(\mathrm{T})$ or $\mathrm{CBS}-\mathrm{QB} 3$, are necessary. Generally speaking, the time required for a calculation with $\operatorname{CCSD}(T)$ is much longer than that with $\mathrm{CBS}-\mathrm{QB} 3$ and the results obtained are not significantly different. Therefore, for the purposes of this study, only the CBS-QB3 method was used in combination with atomization reactions. The gas-phase enthalpy of formation of the DMTZ cation was calculated according to the atomization reaction given in Equation (13) by using Equation (14). The result $\left(\Delta H_{\mathrm{f}}(\mathrm{DMTZ})=773.5 \mathrm{~kJ} \mathrm{~mol}^{-1} ; 7\right.$ min calculation time $)$

\begin{tabular}{|c|c|c|c|c|}
\hline \multirow[t]{2}{*}{ Method } & \multicolumn{2}{|c|}{ Equation (9) } & \multicolumn{2}{|c|}{ Equation (10) } \\
\hline & $\Delta H_{\mathrm{f}}^{0}\left[\mathrm{~kJ} \mathrm{~mol}{ }^{-1}\right]$ & $t[\mathrm{~min}]$ & $\Delta H_{\mathrm{f}}^{0}\left[\mathrm{~kJ} \mathrm{~mol}{ }^{-1}\right]$ & $t[\mathrm{~min}]$ \\
\hline $\mathrm{B} 3 \mathrm{LYP} / 6-311+\mathrm{G}(2 \mathrm{~d}, \mathrm{p})$ & 790.0 & 8 & 800.0 & 6 \\
\hline B3LYP/6-311 + + G(3df,3pd)//B3LYP/6-311 + G(2d,p) & 786.8 & 11 & 795.4 & 8 \\
\hline B3LYP/aug-cc-pVTZ//B3LYP/6-311 + G(2d,p) & 788.2 & 16 & 797.2 & 12 \\
\hline $\operatorname{CCSD}(\mathrm{T}) /$ aug-cc-pVTZ//B3LYP/6-311 + G(2d,p) & 765.5 & 822 & 759.8 & 654 \\
\hline CBS-QB3 & 770.6 & 11 & 764.1 & 8 \\
\hline
\end{tabular}
is very close to that described above with the reaction shown in Equation (9).

Table 2. Calculated enthalpies of formation of the DMTZ cation in the gas phase. 


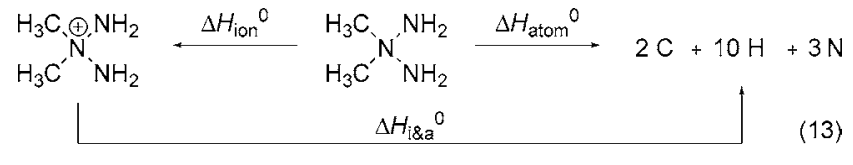

$$
\begin{aligned}
\Delta H_{\mathrm{f}}{ }^{0}\left(\mathrm{DMTZ}^{+}\right)= & 2 \times \Delta H_{\mathrm{f}, \text { exptl }}{ }^{0}(\mathrm{C})+10 \times \Delta H_{\mathrm{f}, \text { exptl }}{ }^{0}(\mathrm{H}) \\
& +3 \times \Delta H_{\mathrm{f}, \text { exptl }}{ }^{0}(\mathrm{~N})-\Delta H_{\mathrm{i} \& \mathrm{a}, \text { calcd }}{ }^{0}
\end{aligned}
$$

\section{Anions and Corresponding DMTZ Salts}

In the case of the azide anion, the protonation reaction shown in Equation (15) was used instead of an isodesmic reaction. However, as mentioned above, when using atomization reactions, the results of this calculation are highly dependent on the level of theory used.

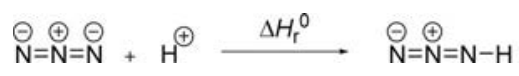

Table 3 collects the enthalpies of formation of the azide anion at different levels of theory, as well as those of the corresponding salt 1 calculated by using Equation (2). The lattice enthalpies were determined by using both the coefficients of Jenkins ${ }^{[91]}$ and Gutowski. ${ }^{[97]}$ Table 4 collects the CBS-QB3 calculated enthalpies of formation of the different ions studied herein, and those of the salts by using both Jenkins and Gutowski coefficients with atomization reactions.

The enthalpy of formation determined previously by using bomb calorimetry was $(352.0 \pm 59.7) \mathrm{kJ} \mathrm{mol}^{-1} .{ }^{[102]}$ Regardless of the uncertainty associated with this measurement, it appears that the calculated values obtained by using the coefficients of Gutowski are in better agreement with the experimental value, whereas using the coefficients of Jenkins leads to a systematic overestimation of the experimental value by around $80 \mathrm{~kJ} \mathrm{~mol}^{-1}$. The same trend is found when using the atomization reaction shown in Equation (16).

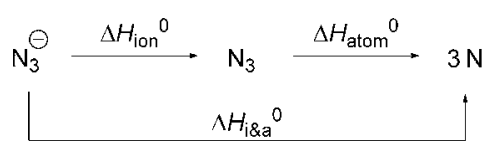

Table 4. Calculated enthalpies of formation of salts 1-6, hydrazinium 5,5'-azobistetrazolate (HZT), and triazanium 5,5'-azobistetrazolate (TZZT) in the solid state by using the CBS-QB3 method (see below for the atomization reactions). ${ }^{[a]}$

\begin{tabular}{llccr} 
Salt & \multicolumn{3}{c}{$\Delta H_{\mathrm{f}}^{0}\left[\mathrm{~kJ} \mathrm{~mol}{ }^{-1}\right]$} & \multicolumn{1}{c}{$t$} \\
& Ion & Salt (Jenkins) & Salt (Gutowski) & {$[\mathrm{min}]$} \\
\hline $\mathbf{1}$ & 190.5 & 416.2 & 333.1 & 8 \\
$\mathbf{2}$ & 179.1 & 442.7 & 348.2 & 14 \\
$\mathbf{3}$ & 789.2 & 1140.0 & - & 1140 \\
$\mathbf{4}$ & 103.8 & 380.9 & 282.6 & 31 \\
$\mathbf{5}$ & -246.0 & 42.3 & -59.3 & 300 \\
$\mathbf{6}$ & -143.3 & 122.1 & 27.2 & 22 \\
HZT & 765.4 & 949.4 & - & 1140 \\
TZZT & 861.4 & 1202.6 & - & 1140 \\
\hline
\end{tabular}

[a] lon =azide, 5-aminotetrazolate, 5,5'-azobistrazolate, 5-nitrotetrazolate, nitroformate, and dinitramide anions for salts 1-6, and hydrazinium and triazanium cations for HZT and TZZT, respectively.

The experimental values available in the literature allow the enthalpy of formation of the 5-aminotetrazolate anion to be determined by using both the protonation reaction shown in Equation (17) and the isodesmic reaction shown in Equation (18). The calculated values are presented in Tables 5 and 6, respectively. Again, the enthalpy of formation calculated by using the B3LYP hybrid functional is systematically higher than those obtained by using $\operatorname{CCSD}(\mathrm{T})$ and $\mathrm{CBS}-\mathrm{QB} 3$. Based on calorimetric measurements, the experimental heat of formation of the compound is $(335.2 \pm 34.7) \mathrm{kJ} \mathrm{mol}^{-1}$. Again, the best match is found when using the coefficients of Gutowski, whereas those of Jenkins lead to an overestimation of around $95 \mathrm{~kJ} \mathrm{~mol}^{-1}$. In this case, the experimental uncertainty is smaller and only the highly correlated $\operatorname{CCSD}(\mathrm{T})$ and $\mathrm{CBS}-\mathrm{QB} 3$ methods give values within the range of experimental error (from 300.5 to $369.9 \mathrm{~kJ} \mathrm{~mol}^{-1}$ ). Additionally, the values obtained by using the protonation reaction shown in Equation (17), are closer to the experimental value than those obtained by using the isodesmic reaction shown in Equation (18).<smiles></smiles>

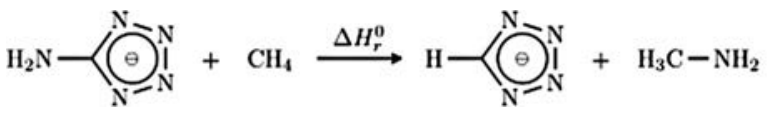

\begin{tabular}{|c|c|c|c|c|}
\hline \multirow[t]{2}{*}{ Method } & \multicolumn{3}{|c|}{$\Delta H_{\mathrm{f}}^{0}\left[\mathrm{~kJ} \mathrm{~mol}{ }^{-1}\right]$} & \multirow{2}{*}{$\begin{array}{l}t \\
{[\mathrm{~min}]}\end{array}$} \\
\hline & Anion & Salt (Jenkins) & Salt (Gutowski) & \\
\hline $\mathrm{B} 3 \mathrm{LYP} / 6-311+\mathrm{G}(2 \mathrm{~d}, \mathrm{p})$ & 182.7 & 425.0 & 341.9 & 9 \\
\hline B3LYP/6-311 + + G(3df,3pd)//B3LYP/6-311 + G(2d,p) & 186.3 & 425.4 & 342.3 & 12 \\
\hline B3LYP/aug-cc-pVTZ//B3LYP/6-311 + G(2d,p) & 186.8 & 427.3 & 344.2 & 17 \\
\hline CCSD(T)/aug-cc-pVTZ//B3LYP/6-311 + G(2d,p) & 188.8 & 406.6 & 323.5 & 828 \\
\hline CBS-QB3 & 186.9 & 409.8 & 326.7 & 11 \\
\hline
\end{tabular}

Table 3. Calculated enthalpies of formation of the azide anion in the gas phase and of salt 1 in the solid state, according to the isodesmic reaction shown in Equation (9) and the protonation reaction shown in Equation (15). 
Table 5. Calculated enthalpies of formation of the 5-aminotetrazolate anion in the gas phase and that of salt $\mathbf{2}$ in the solid state, according to the isodesmic reaction shown in Equation (9) and the protonation reaction shown in Equation (17).

\begin{tabular}{llll} 
Method & Anion & $\begin{array}{c}\Delta H_{\mathrm{f}}^{0}\left[\mathrm{~kJ} \mathrm{~mol}^{-1}\right] \\
\text { Salt (Jenkins) }\end{array}$ & $\begin{array}{c}t \\
\text { [min] }\end{array}$ \\
\hline B3LYP/6-311+G(2d,p) & 181.1 & 461.3 & 366.8 \\
B3LYP/6-311++G(3df,3pd)//B3LYP/6-311+G(2d,p) & 186.0 & 368.5 \\
B3LYP/aug-cc-pVTZ//B3LYP/6-311+G(2d,p) & 187.0 & 463.0 & 370.9 \\
CCSD(T)/aug-cc-pVTZ//B3LYP/6-311+G(2d,p) & 177.9 & 465.3 & 339.1 \\
CBS-QB3 & 172.8 & 433.6 & 336.1
\end{tabular}

Table 6. Calculated enthalpies of formation of the 5-aminotetrazolate anion in the gas phase and that of salt $\mathbf{2}$ in the solid state, according to the isodesmic reactions shown in Equations (9) and (18).

\begin{tabular}{|c|c|c|c|c|}
\hline \multirow[t]{2}{*}{ Method } & \multicolumn{3}{|c|}{$\Delta H_{\mathrm{f}}^{0}\left[\mathrm{~kJ} \mathrm{~mol}{ }^{-1}\right]$} & \multirow{2}{*}{$\begin{array}{l}t \\
{[\mathrm{~min}]}\end{array}$} \\
\hline & Anion & Salt (Jenkins) & Salt (Gutowski) & \\
\hline B3LYP/6-311 + G(2d,p) & 205.1 & 485.3 & 390.8 & 13 \\
\hline B3LYP/6-311 + + G(3df,3pd)//B3LYP/6-311 + G(2d,p) & 205.1 & 482.0 & 387.6 & 17 \\
\hline B3LYP/aug-cc-pVTZ//B3LYP/6-311 + G(2d,p) & 205.3 & 483.6 & 389.2 & 23 \\
\hline CCSD(T)/aug-cc-pVTZ//B3LYP/6-311 + G(2d,p) & 204.2 & 459.8 & 365.4 & 2736 \\
\hline CBS-QB3 & 202.7 & 463.4 & 369.0 & 20 \\
\hline
\end{tabular}

Similarly to that observed for azide salt 1 , the heat of formation of the 5-aminotetrazolate salt 2 calculated by using the atomization reaction shown in Equation (19) at the CBS-QB3 level of theory is higher that than obtained by using the protonation reaction shown in Equation (17) by around $10 \mathrm{~kJ} \mathrm{~mol}^{-1}$ (Tables 4 and 5).

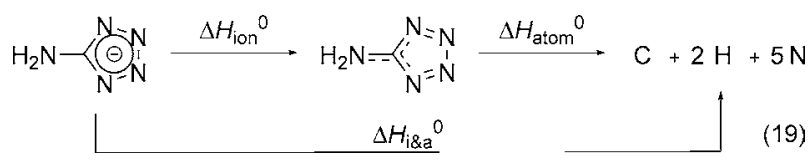

The heat of formation of the salt calculated by using the coefficients of Gutowski (Table 4) and the atomization reaction shown in Equation (19) $\left(\Delta H_{\mathrm{f}}=348.2 \mathrm{~kJ} \mathrm{~mol}^{-1}\right)$ falls within the margins of error of the experimental value.

At this point, it is clear that the slight additional precision of a $\operatorname{CCSD}(\mathrm{T})$ calculation compared with that of a CBS-QB3 calculation is not worth the much longer computational time required. As such, the $\operatorname{CCSD}(T)$ method was no longer used as for the remaining compounds.

For the 5,5'-azobistetrazolate salt 3 , that is, a $M_{2} X$ compound, only the Jenkins coefficients are reported in the literature. Tables 7 and 4 contain the values for the enthalpies of formation obtained by using the isodesmic reaction shown in

Table 7. Calculated enthalpies of formation of the $5,5^{\prime}$-azobistrazolate anion in the gas phase and that of salt $\mathbf{3}$ in the solid state, according to the isodesmic reactions shown in Equations (9) and (20).

\begin{tabular}{lllr} 
Method & \multicolumn{2}{c}{$\Delta H_{\mathrm{f}}^{0}\left[\mathrm{~kJ} \mathrm{~mol}^{-1}\right]$} & \multicolumn{1}{l}{$t$} \\
& Anion & Salt (Jenkins) & \multicolumn{1}{c}{$[\mathrm{min}]$} \\
\hline B3LYP/6-311+G(2d,p) & 834.0 & 1217.8 & 38 \\
B3LYP/6-311+ + G(3df,3pd)//B3LYP/6-311+G(2d,p) & 836.2 & 1213.7 & 45 \\
B3LYP/aug-cc-pVTZ//B3LYP/6-311+ G(2d,p) & 836.7 & 1216.9 & 56 \\
CBS-QB3 & 830.5 & 1175.6 & 1194
\end{tabular}

Equation (20) and the atomization reaction shown in Equation (21), respectively. The general trends discussed above are also observed for this compound.

The experimental heat of formation of this compound is $(690.6 \pm 55.4) \mathrm{kJ} \mathrm{mol}^{-1}$ when using benzoic acid as a combustion auxiliary and $(1102.7 \pm 39.2) \mathrm{kJ} \mathrm{mol}^{-1}$ when using paraffin oil. The only calculated value that falls within the margin of error of the experimental values is that computed by using the CBS-QB3 method and the atomization reaction shown in Equation (21) $\left(\Delta H_{\mathrm{f}}=1140.0 \mathrm{~kJ} \mathrm{~mol}^{-1}\right)$; this prompted us to believe that an undesired acid-base reaction probably took place between the energetic salt and benzoic acid when the latter was used as an auxiliary. All enthalpies of formation calculated by using isodesmic reactions are well above the experimental value, in particular, that obtained with B3LYP.

The isodesmic and atomization reactions shown in Equations (22) and (23), respectively, used for the 5-nitrotetrazolate anion resemble those used above for the 5-aminotetrazolate anion. The calculated enthalpies of formation for the 5-nitrotetrazolte salt 4 when using both reactions are presented in Tables 8 and 4.

Owing to the issues encountered when using benzoic acid as a combustion auxiliary mentioned above, we chose to replace this with paraffin oil to measure the heat of combustion of 5 -nitrotetrazolate salt 4 . However, the numerous tests performed with this compound left behind significant amounts of soot, which rendered the obtained results unusable. Therefore, we returned to using benzoic acid as the auxiliary and obtained an experimental value of $(182.2 \pm 16.4) \mathrm{kJ} \mathrm{mol}^{-1}$. This value is well below the calculated values obtained by using different methods with the Gutowski coefficients. We believe that the reason for this lack of agreement comes, as seen above, from an acid-base reaction between the salt and the auxiliary. However, 


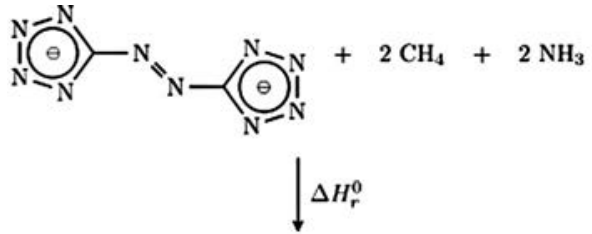<smiles>N=N[NH3+]</smiles>

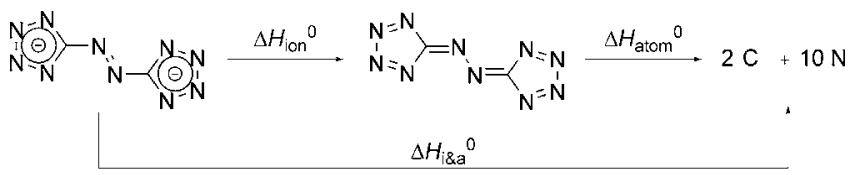
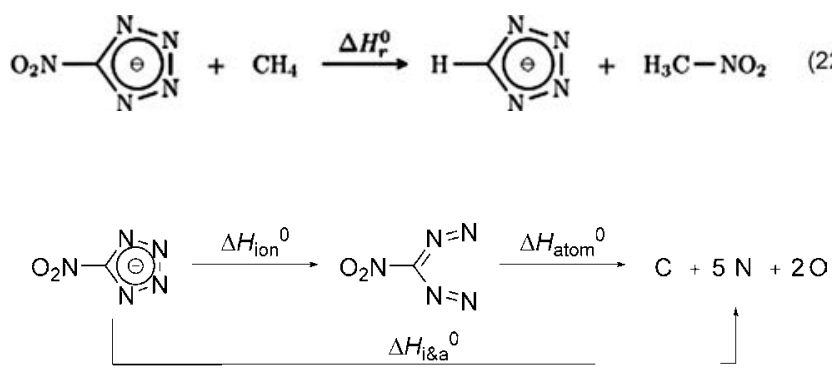

if the reaction with the paraffin oil had gone to completion or if there were no secondary reaction with benzoic acid, we believe that the experimental values would agree with those calculated with CBS-QB3 $\left(\Delta H_{\mathrm{f}}=282.6 \mathrm{~kJ} \mathrm{~mol}^{-1}\right.$, obtained using the atomization reaction and Gutowski coefficients).

Equations (24) and (25) show the protonation and atomization reactions, respectively, used to calculate the heat of formation of the nitroformate salt $\mathbf{5}$. The calculated values are given in Tables 9 and 4. Unfortunately, we were not able to obtain the nitroformate salt in sufficiently pure form to per- form combustion measurements. However, based on the results discussed above, it is fair to assume that the experimental heat of formation of the nitroformate salt should be close to that of the CBS-QB3 calculated value obtained using the atomization method and Gutowski coefficients for which $\Delta H_{\mathrm{f}}=$ $-59.3 \mathrm{~kJ} \mathrm{~mol}^{-1}$.

$$
\begin{aligned}
& \underset{\mathrm{NO}_{2}}{\stackrel{\ominus}{\mathrm{N}} \underset{\mathrm{NO}_{2}}{\mathrm{NO}_{2}}}+\mathrm{H}^{\oplus} \stackrel{\Delta H_{r}^{0}}{\longrightarrow} \mathrm{H}-\mathrm{C} \underset{\mathrm{NO}_{2}}{\stackrel{\mathrm{NO}_{2}}{-} \mathrm{NO}_{2}}
\end{aligned}
$$

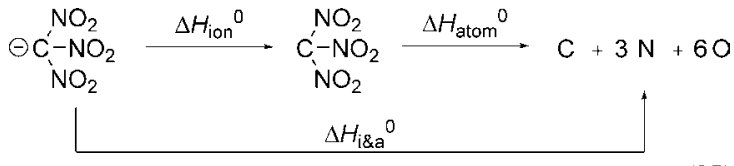

As for the nitroformate salt above, dinitramide salt 6 could not be obtained in high enough purity to perform combustion measurements. The lack of reliable experimental heats of formation for the dinitramide anion and its derivatives make the atomization method the method of choice for calculating the heat of formation of this compound. This was estimated to be $\Delta H_{\mathrm{f}}=27.2 \mathrm{~kJ} \mathrm{~mol}^{-1}$, by using Equation (26) and the Gutowski coefficients to calculate the lattice enthalpy (Table 4).

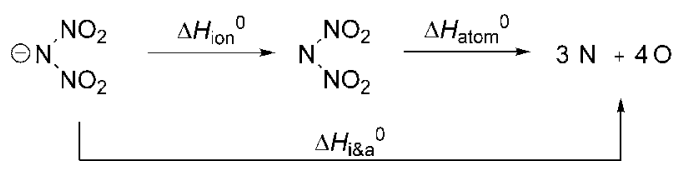

\section{Other Nitrogen-Rich Salts}

At this point, it was interesting for us to apply the method described above to other nitrogen-rich salts containing a different cation from DMTZ. Of all compounds available in the literature, hydrazinium 5,5'-azobistetrazolate (HZT) has been extensively

Table 8. Calculated enthalpies of formation of the 5-nitrotetrazolate anion in the gas phase and of salt $\mathbf{4}$ in the solid state, according to the isodesmic reactions shown in Equations (9) and (22).

\begin{tabular}{llcr} 
Method & Anion & $\begin{array}{c}\Delta H_{\mathrm{f}}^{0}\left[\mathrm{~kJ} \mathrm{~mol}^{-1}\right] \\
\text { Salt (Jenkins) }\end{array}$ & $\begin{array}{l}t \\
\text { [min] }\end{array}$ \\
\hline B3LYP/6-311+G(2d,p) & 138.2 & 431.9 & 333.5 \\
B3LYP/6-311+ +G(3df,3pd)//B3LYP/6-311+G(2d,p) & 140.6 & 431.1 & 332.8 \\
B3LYP/aug-cc-pVTZ//B3LYP/6-311+G(2d,p) & 140.7 & 432.6 & 33.2 \\
CBS-QB3 & 138.4 & 412.7 & 314.4
\end{tabular}

Table 9. Calculated enthalpies of formation of the nitroformate anion in the gas phase and of salt $\mathbf{5}$ in the solid state, according to isodesmic reaction shown in Equation (9) and the protonation reaction shown in Equation (24).

\begin{tabular}{|c|c|c|c|c|}
\hline \multirow[t]{2}{*}{ Method } & \multicolumn{3}{|c|}{$\Delta H_{\mathrm{f}}^{0}\left[\mathrm{~kJ} \mathrm{~mol}{ }^{-1}\right]$} & \multirow{2}{*}{$\begin{array}{l}t \\
{[\mathrm{~h}]}\end{array}$} \\
\hline & Anion & Salt (Jenkins) & Salt (Gutowski) & \\
\hline B3LYP/6-311 + G(2d,p) & -265.7 & 39.1 & -62.5 & 1.1 \\
\hline B3LYP/6-311 + + G(3df,3pd)//B3LYP/6-311 + G(2d,p) & -259.6 & 42.0 & -59.6 & 1.2 \\
\hline B3LYP/aug-cc-pVTZ//B3LYP/6-311 + G(2d,p) & -260.4 & 42.6 & -59.0 & 1.4 \\
\hline CBS-QB3 & -232.0 & 53.4 & -48.2 & 11.5 \\
\hline
\end{tabular}


described by Klapötke et al., ${ }^{[95]}$ and presents the advantage of being based on the 5,5'-azobistetrazolate anion, which had already been calculated for 3 (see above). The second nitrogenrich salt considered herein was triazanium 5,5'-azobistetrazolate (TZZT), which has not yet been described in the literature.

Table 10 contains a summary of the methods and results obtained for the heats of formation of HZT, and provides a comparison with the results previously published by Klapötke et al. ${ }^{[95]}$ For our calculations, we used the atomization method with Equation (21) for the anionic part and Equation (27) for the cationic part. Because only Jenkins coefficients are available for 1:2-type salts, we calculated the lattice enthalpies by using the Jenkins values to obtain a heat of formation of $\Delta H_{\mathrm{f}}=949.4 \mathrm{~kJ} \mathrm{~mol}^{-1}$ (Table 4) by using the CBS-QB3 method.
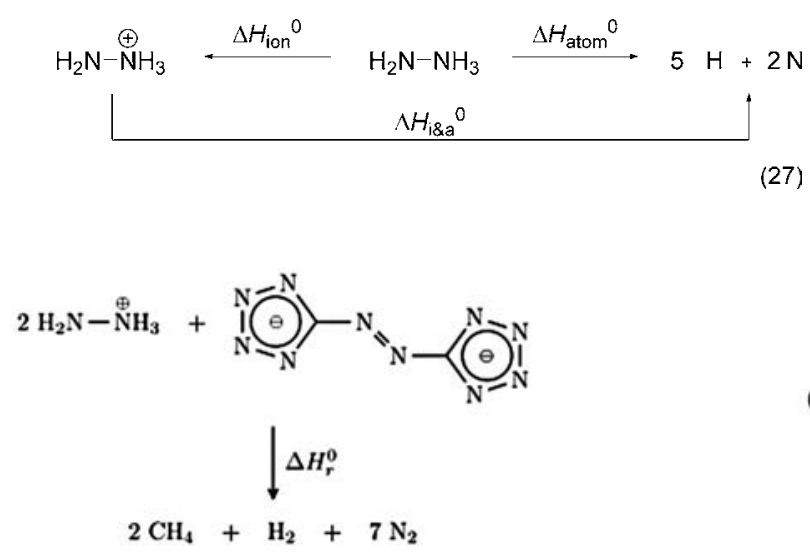

Table 10. Comparison of experimental and calculated values obtained for HZT.

\begin{tabular}{|c|c|c|}
\hline Parameters & This work & Klapötke et al. ${ }^{[95]}$ \\
\hline reaction & $\begin{array}{l}\text { atomization [Eqs. (21) and } \\
(27)]\end{array}$ & $\begin{array}{l}\text { other [Eq. (28), non iso- } \\
\text { desmic] }\end{array}$ \\
\hline method & CBS-QB3 & MP2(FULL)/6-311 + G(d,p) \\
\hline$V($ salt $)\left[\AA^{3}\right]$ & 266.1 (B3LYP/6-31G(d,p)) & 334.5 (exptl) \\
\hline$\Delta H_{\mathrm{L}}\left[\mathrm{kJ} \mathrm{mol}{ }^{-1}\right]$ & 1371 & 1257 \\
\hline $\begin{array}{l}\Delta H_{\mathrm{f}}^{0} \text { calcd } \\
{\left[\mathrm{kJ} \mathrm{mol}^{-1}\right]}\end{array}$ & 949 & 1105 \\
\hline $\begin{array}{l}\Delta H_{\mathrm{f}}^{0} \text { exptl } \\
{\left[\mathrm{kJ} \mathrm{mol}{ }^{-1}\right]}\end{array}$ & $\varnothing$ & $858^{[a]}$ \\
\hline
\end{tabular}

[a] Obtained with the combustion auxiliary benzoic acid.

A closer look at Table 10 reveals that the volume calculated herein at the B3LYP/6-31G $(d, p)$ level of theory $\left(266.1 \AA^{3}\right)$ differs significantly from that found experimentally (X-ray crystallography) by Klapötke et al. $\left(334.5 \AA^{3}\right) .^{[95]}$ This is surprising because the method used herein to calculate the volume is in very good agreement with the experimental data of the DMTZ prepared and described herein (Table 1). As a consequence of this volume difference, the lattice enthalpies $\left(\Delta H_{\mathrm{L}}=1371 \mathrm{~kJ} \mathrm{~mol}^{-1}\right.$ vs. $1257 \mathrm{~kJ} \mathrm{~mol}^{-1}$ for Klapötke et al. $\left.{ }^{[95]}\right)$ and the heats of formation $\left(\Delta H_{\mathrm{f}}=949 \mathrm{~kJ} \mathrm{~mol}^{-1}\right.$ vs. $1105 \mathrm{~kJ} \mathrm{~mol}^{-1}$ for Klapötke et al. $\left.{ }^{[95]}\right)$ are also significantly different. Based on our experience of using the B3LYP hybrid functional for isodesmic reactions (sys- tematic overestimation of $\Delta H_{\mathrm{f}}^{0}$ ), we believe that the $\mathrm{MP} 2(\mathrm{FULL}) / 6-311+\mathrm{G}(\mathrm{d}, \mathrm{p})$ level of theory is insufficient to give satisfactory values, especially with a reaction that is not isodesmic. Consequently, the heat of formation obtained by using this method in association with Equation (28) probably overestimates the real value. On the other hand, knowing that Klapötke et al. tend to use benzoic acid for their calorimetric measurements, ${ }^{[95]}$ it is likely that their experimental values are underestimated, as in the case of $\mathbf{3}$. Therefore, considering the good agreement between our calculated values obtained by using atomization reactions with the composite method CBSQB3 and our experimental values with paraffin oil as the combustion auxiliary, we believe that the heat of formation calculated by our method is probably the closest to the real value. Notably, the value we calculated by using this method was between that calculated by Klapötke et al., ${ }^{\left[{ }^{[5]}\right.}$ which we consider to be overestimated, and that measured by the same authors, which we consider to be underestimated.

Now that the heat of formation of HZT has been calculated, it is interesting to compare it with those of $\mathbf{3}$ and TZZT, which is assumed to be stable under ambient conditions for the purposes of our comparison [Eq. (29)].

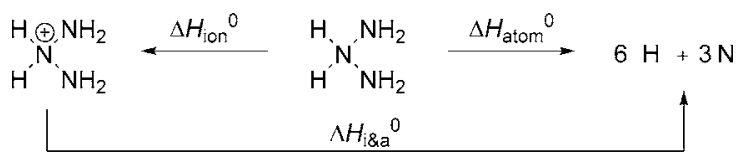

Following the same procedures as those described above, we calculated a heat of formation of $1202.6 \mathrm{~kJ} \mathrm{~mol}^{-1}$ for TZZT (Table 4). In practice, in the thermodynamic codes used to evaluate the performance of energetic compounds, the heat of formation is expressed per mass unit. The heat of formation in $\mathrm{kJ} \mathrm{kg}^{-1}$ increases in the order $3\left(\Delta H_{\mathrm{f}}=3603.8 \mathrm{~kJ} \mathrm{~kg}^{-1}\right), \mathrm{HZT}$ $\left(\Delta H_{\mathrm{f}}=4124.4 \mathrm{~kJ} \mathrm{~kg}^{-1}\right)$, and TZZT $\left(\Delta H_{\mathrm{f}}=4621.5 \mathrm{~kJ} \mathrm{~kg}^{-1}\right)$, when using CBS-QB3 values from the atomization reactions described above. This tendency to increase from DMTZ to TZZT puts into perspective the positive effect on the performance of the extra $\mathrm{N}-\mathrm{N}$ bond and the negative effect of a higher carbon content.

To further confirm the validity of the procedure described above to compute $\Delta H_{\mathrm{f}}^{0}(\mathrm{~g})$ (i.e., CBS-QB3 calculations associated with atomization reactions) based on our experimental results, we also considered other experimental $\Delta H_{\mathrm{f}}{ }^{\mathrm{g}}(\mathrm{g})$ values reported in the literature. Table 11 contains the predicted values for all compounds involved in the above isodesmic and protonation reactions for which experimental data was available.

Overall, there is a good agreement between experimental and calculated values. However, the agreement between calculated and experimental values for the tetrazolate anion and nitroform is lower than that for the smaller anions. Before questioning the method used herein, other experimental sources would be needed to verify if the enthalpies of formation reported herein were precise enough. If there were still a lack of agreement with the new data, it would be necessary to com- 
Table 11. Comparison of experimental $\Delta H_{\mathrm{f}}^{0}(\mathrm{~g})$ values with the corresponding theoretical values (obtained by using the CBS-QB3 method associated with atomization reactions).

\begin{tabular}{lcc} 
Compounds & \multicolumn{2}{c}{$\Delta H_{\mathrm{f}}{ }^{\mathrm{g}}(\mathrm{g})\left[\mathrm{kJ} \mathrm{mol}{ }^{-1}\right]$} \\
& CBS-QB3/atomization & \multicolumn{1}{c}{ Exptl } \\
\hline $\mathrm{NH}_{3}$ & -43.8 & $-45.9^{[113]}$ \\
$\mathrm{NH}_{4}{ }^{+}$ & 632.2 & $630.2^{[114]}$ \\
$\mathrm{CH}_{4}$ & -74.2 & $-74.9^{[113]}$ \\
$\mathrm{H}-\mathrm{N}=\mathrm{N}-\mathrm{H}$ (cis) & 223.1 & $213.0^{[113]}$ \\
$\mathrm{N}_{3}^{-}$ & 190.5 & $180.7^{[115]}$ \\
$\mathrm{HN}_{3}$ & 291.7 & $294.1^{[115]}$ \\
$\mathrm{NH}_{2} \mathrm{NH}_{2}$ & 99.8 & $95.4^{[113]}$ \\
$\mathrm{CH}_{3} \mathrm{NH}_{2}$ & -19.6 & $-23.0^{[113]}$ \\
$\mathrm{CH}_{3} \mathrm{NO}_{2}$ & -82.5 & $-74.9^{[115]}$ \\
$\left(\mathrm{CH}_{3}\right)_{2} \mathrm{NNH}_{2}$ & 83.9 & $83.3^{[116]}$ \\
tetrazolate anion & 174.1 & $200.4^{[117]}$ \\
5-aminotetrazole & 324.1 & $323.8^{[97]}$ \\
$\mathrm{HC}\left(\mathrm{NO}_{2}\right)_{3}$ & -20.8 & $-0.8^{[118]}$
\end{tabular}

pare the experimental and calculated geometric parameters (bond lengths and angles, as well as dihedral angles) to find the cause of these differences. Unfortunately, such experimental data in the gas phase is scarce in the literature, especially for ionic species, such as the tetrazolate anion, or "exotic" molecules, such as nitroform. Therefore, we conclude that, based upon the results obtained for the compounds studied herein, it appears that the combination of the CBS-QB3 method with atomization reactions is best suited to precisely predict gasphase enthalpies of formation.

\section{Specific Impulses}

Once the heat of formation of a given compound is known, and using its molecular formula, the detonation parameters (for high explosives) and specific impulses ( $I_{\text {sp }}$; for propellants) can be calculated by using a computer code. For all $l_{\text {sp }}$ calculations reported in this section, we used the OPHELIE code, which is a modification of the CEC71 program (Chemical Equilibrium Calculations) ${ }^{[119]}$ used by NASA to calculate theoretical rocket performance. These simulations are typically carried out with a combustion chamber pressure of $70 \mathrm{~atm}$ and an exit pressure of $1 \mathrm{~atm}$. Given the properties of the DMTZ salts studied herein, they could potentially be used as solid or liquid (dissolving the salts in a solvent) propulsion compounds. For DMTZ salts 1-6, as well as for HZT and TZZT, we carried out two simulations: one with the calculated enthalpies of formation and one with (if available) the experimental values from bomb calorimetry, for comparative purposes (Table 12). In all cases, we replaced aluminum (typically used for such formulations) with the energetic salts mentioned above. These calculations were carried out for solid propulsion by using the following mass ratio: $68 \%$ ammonium perchlorate, 18\% energetic salt, and $14 \%$ hydroxyl-terminated polybutadiene (HTPB). The ratio between the oxidizer and reducer was set at 2.125 . Under these conditions, commercial mixtures based on aluminum achieve $I_{\text {sp }}$ values of $265.3 \mathrm{~s}$.

The $I_{\mathrm{sp}}$ values calculated for the formulations described above, obtained by using calculated and experimentally ob-
Table 12. Specific impulses $\left(I_{\mathrm{sp}}\right)$ calculated for solid propulsion by replacing aluminum with nitrogen-rich salts $1-6, H Z T$, and TZZT.

\begin{tabular}{|c|c|c|c|c|}
\hline Salt & $\begin{array}{l}\text { Type of } \\
\text { value }\end{array}$ & \multicolumn{2}{|c|}{$\Delta H_{\mathrm{f}}^{0}$} & $\begin{array}{l}l_{\mathrm{sp}} \\
{[\mathrm{s}]}\end{array}$ \\
\hline \multirow[t]{2}{*}{1} & calcd & 333.1 & 2819.5 & 229.3 \\
\hline & exptl & 352.0 & 2979.5 & 230.0 \\
\hline \multirow[t]{2}{*}{2} & calcd & 348.2 & 2173.8 & 224.9 \\
\hline & exptl & 335.2 & 2092.6 & 224.5 \\
\hline \multirow[t]{2}{*}{3} & calcd & 1140.0 & 3603.8 & 230.8 \\
\hline & exptl & 1102.7 & 3485.9 & 230.3 \\
\hline 4 & calcd & 282.6 & 1486.1 & 233.2 \\
\hline 5 & calcd & -59.3 & -262.2 & 242.3 \\
\hline 6 & calcd & 27.2 & 149.3 & 241.3 \\
\hline HZT & calcd & 949.4 & 4124.4 & 237.6 \\
\hline TZZT & calcd & 1202.6 & 4621.5 & 240.5 \\
\hline
\end{tabular}

tained heats of formation, do not differ significantly (less than $1 \mathrm{~s})$. This supports the validity of the method used for the calculations, in particular, the composite method CBS-QB3 associated with atomization reactions. However, the $I_{\text {sp }}$ values calculated herein for mixtures in which aluminum has been completely replaced with one of the energetic salts, are lower than those of the reference systems with pure aluminum. Therefore, it would be useful to study other formulations based on mixtures of aluminum with one of the nitrogen-rich salts described herein.

\section{Conclusion}

In view of the different calculation methods used herein to predict gas-phase enthalpies of formation of nitrogen-rich salts, the method that appears to be the simplest and most reliable is that of CBS-QB3 associated with atomization reactions. This method presents the additional advantage of being based on reliable values (the enthalpies of formation of the atoms). This is particularly important because enthalpies of formation (especially for new compounds) are often not available from the literature. Furthermore, even if these values have been described, their validity might be subject to discussion, as illustrated by the lack of agreement between the gas-phase heat of formation of the DMTZ cation obtained herein and the previously calculated value, ${ }^{[54]}$ which seems to significantly overestimate the real value. To convert gas-phase heats of formation into those of the solid phase, the lattice enthalpy (in the case of ionic compounds) needs to be known accurately. The latter can be evaluated based on the volume of the salt calculated at the B3LYP/6-31G $(d, p)$ level of theory or by using the experimental value (e.g., from X-ray measurements at room temperature) and either Jenkins or Gutowski coefficients in the formulas developed by Jenkins et al. The Gutowski coefficients appear to give the best agreement with experimental values for the salts of the DMTZ cation in this study, however, their field of application is limited to 1:1 salts. Nevertheless, the predicted values tend to be higher than those obtained experimentally through combustion measurements, so that the true values are expected to lie somewhere in between calculated and experimental values. 


\section{Experimental Section}

\section{Computational Details}

The chemical quantum calculations were carried out by using Gaussian 09 software. ${ }^{[8]}$ We used GaussView 5 to prepare the Gaussian job files and analyze the results of the output file.

For all calculations, we used a local cluster belonging to the Analytical Science Institute (UMR 5280) in Lyon. Each node ran the Linux Red Hat Enterprise (64 bits) operating system and comprised two hexacore Intel Xeon X5650 processors clocked at $2.66 \mathrm{GHz}$ and $24 \mathrm{~GB}$ of memory (DDR3, $1333 \mathrm{MHz}$ ). Each Gaussian job was run on a single node, with all 12 cores available and 22 GB of memory allocated.

Once the method was chosen, the equilibrium geometry (i.e., ground state) was sought. This geometry is a stationary point corresponding to the global minimum on the potential energy hypersurface and is characterized by the absence of imaginary frequencies. Frequency calculations were carried out at the same level of theory as that used for geometry optimization. To ensure that the optimized geometry was a true minimum and not just a local minimum (also characterized by the absence of imaginary frequencies), the structure was inspected critically (steric hindrance, unexpected intramolecular interactions, ...) or by using molecular dynamics. At this point, we carried out a single-point energy calculation at a higher level of theory than that used for the geometry optimization. The nomenclature used herein was method2/base2// method $1 /$ base 1 , in which method 1 was used in combination with base 1 for geometry optimization, whereas method 2 and base 2 were used for single-point calculations.

\section{X-ray Crystallography}

A suitable crystal was selected and mounted on a Gemini kappageometry diffractometer (Agilent Technologies, UK, Ltd.) equipped with an Atlas CCD detector with Cu radiation $(\lambda=1.5418 \AA)$. Intensities were collected at $150 \mathrm{~K}$ by using the CrysalisPro software. ${ }^{[120]}$ Reflection indexing, unit-cell parameter refinements, Lorentz polarization corrections, peak integration, and background determination were carried out by using the CrysalisPro software. ${ }^{[120]}$ An analytical absorption correction was applied by using the modeled faces of the crystal. ${ }^{[121]}$ The resulting set of $h k l$ values was used for structure solution and refinement. The structures were solved by direct methods with $\mathrm{SIR} 7^{[122]}$ and least-squares refinement on F2 was achieved with the CRYSTALS software. ${ }^{[123]}$ All non-hydrogen atoms were refined anisotropically. The hydrogen atoms were all located in a difference map, but those attached to carbon atoms were repositioned geometrically. The hydrogen atoms were initially refined with soft restraints on the bond lengths and angles to regularize their geometry $(\mathrm{C}-\mathrm{H}$ in the range $0.93-0.98, \mathrm{~N}-\mathrm{H}$ in the range $0.86-0.89$, and $\mathrm{O}-\mathrm{H}=0.82 \AA$ ) and $U_{\text {iso }}(\mathrm{H})$ (in the range $1.2-$ 1.5 times $U_{\text {eq }}$ of the parent atom), after which the positions were refined with riding constraints. The Diamond software ${ }^{[124]}$ was used to prepare Figures 2 and 3.

\section{Bomb Calorimetry}

The heats of combustion of the synthesized salts were measured by using a Parr 6200 isoperibol bomb calorimeter equipped with a Parr 1108 oxygen bomb suitable for the combustion of halogenfree materials. The calorimeter was calibrated by using benzoic acid as a standard. Because nitrogen-rich compounds do not gen- erally burn readily, a combustion auxiliary was needed. The samples for bomb calorimetry measurements were prepared by thoroughly mixing the DMTZ salt $(\approx 100 \mathrm{mg})$ with benzoic acid $(\approx 900 \mathrm{mg})$ and pressing the mixture into pellets $(\approx 1 \mathrm{~g})$. Whenever reaction between the DMTZ salt and benzoic acid was observed, the latter was replaced with paraffin oil as follows: the finely powdered DMTZ salt $(\approx 100 \mathrm{mg})$ was scattered in the combustion crucible and paraffin oil ( $\approx 600 \mathrm{mg}$ ) was added uniformly.

\section{Synthesis of salt 5}

A $0.1 \mathrm{molL}^{-1}$ (determined by acidimetric titration) solution of barium hydroxide was prepared by dissolving barium hydroxide octahydrate (ca. $15 \mathrm{~g}, 99.9 \%$ ) in water $(400 \mathrm{~mL})$; all insoluble species were filtered and discarded. This solution $(76.5 \mathrm{~mL}, 7.86 \mathrm{mmol})$ was then added to a solution of hydrazinium nitroformate $(100 \mathrm{~mL}, 15.72 \mathrm{mmol})$. The mixture was stirred for $10 \mathrm{~min}$ and reacted with a solution of 2,2-dimethyltriazanium sulfate ${ }^{[102]}$ in water $(10 \mathrm{~mL})$. Stirring was continued for further $10 \mathrm{~min}$ and the precipitated barium sulfate was filtered through a plug of Celite 545 . The filtrate was concentrated in vacuo to give a wet solid. The residue was then washed with absolute ethanol $(100 \mathrm{~mL})$ and the solvent was stripped. This process was repeated as many times as necessary until a dry solid was obtained. The dry crude product $(2.312 \mathrm{~g}$, $81 \%)$ was recrystallized overnight at $-20^{\circ} \mathrm{C}$ from isopropanol to yield yellow crystals of $\mathbf{5}$ suitable for the $\mathrm{X}$-ray measurements. ${ }^{1} \mathrm{H} N M R \quad\left(500.13 \mathrm{MHz}, \quad\right.$ [D6]DMSO): $\delta=6.30 \quad\left(\mathrm{~s}, \quad 4 \mathrm{H} ; \quad \mathrm{N}^{+} \mathrm{NH}_{2}\right)$, $3.41 \mathrm{ppm}\left(\mathrm{s}, 6 \mathrm{H} ; \mathrm{CH}_{3}\right) ;{ }^{13} \mathrm{C}\left\{{ }^{1} \mathrm{H}\right\} \mathrm{NMR}(125.76 \mathrm{MHz}$, [D6]DMSO): $\delta=$ $150.3 \quad\left(\mathrm{C}\left(\mathrm{NO}_{2}\right)_{3}\right), \quad 59.9 \mathrm{ppm} \quad\left(\mathrm{CH}_{3}\right) ; \quad{ }^{15} \mathrm{~N}\left\{{ }^{1} \mathrm{H}\right\} \mathrm{NMR} \quad(50.68 \mathrm{MHz}$, [D6]DMSO): $\delta=352\left(\mathrm{NO}_{2}\right), 134\left(\mathrm{NH}_{2}\right), 105 \mathrm{ppm}\left(\mathrm{N}^{+}\right) ; \mathrm{FTIR}: \tilde{v}=3321$ $(m), 3280(w), 3241(w), 3187(w), 3135(w), 3060(w), 2640(w)$, $1638(\mathrm{w}), 1611(\mathrm{w}), 1581(\mathrm{w}), 1531(\mathrm{~m}), 1469(\mathrm{~s}), 1429(\mathrm{~m}), 1402$ $(\mathrm{m}), 1367(\mathrm{~m}), 1253(\mathrm{~s}), 1134(\mathrm{~s}), 1101(\mathrm{~s}), 1075(\mathrm{~s}), 991(\mathrm{~m}), 976(\mathrm{~m})$, $962(\mathrm{~m}), 923(\mathrm{~m}), 865(\mathrm{~m}), 850(\mathrm{~s}), 784(\mathrm{~s}), 733(\mathrm{~s}), 710(\mathrm{~m}), 503(\mathrm{w})$, $480 \mathrm{~cm}^{-1}(\mathrm{~m}) ; \quad$ DSC $\quad\left(1.03 \mathrm{mg}, \quad 5^{\circ} \mathrm{Cmin}^{-1}\right): \quad T_{\text {decomp }}=106^{\circ} \mathrm{C}$ $\left(-2887 \mathrm{Jg}^{-1}\right.$, exothermic).

\section{Acknowledgements}

This work is part of the Ph.D. thesis of V.F., who acknowledges financial support by the CNRS (Centre National de la Recherche Scientifique) and the CNES (Centre National d'Études Spatiales). V.F. would like to thank Dr. P. Mignon for his assistance in using the cluster, Dr. E. Jeanneau for the crystal structure measurements, and Dr. F. R. Clemente from the Gaussian support team for his valuable help concerning the volume calculations.

Keywords: energetic materials - heterocycles - nitrogen • quantum chemistry $\cdot$ thermodynamics

[1] D. C. Young, Computational Chemistry: A Practical Guide for Applying Techniques to Real World Problems, Wiley, Hoboken, 2004.

[2] M. J. Kamlet, S. J. Jacobs, J. Chem. Phys. 1968, 48, 23.

[3] P. Politzer, J. S. Murray, M. E. Grice, P. Sjoberg, Chemistry of Energetic Materials, Academic Press, New York, 1991.

[4] J. Kohler, R. Meyer, Explosives, 4th ed., VCH, Weinheim, 1993.

[5] C. L. Mader, Numerical Modeling of Explosives and Propellants, 2nd ed., CRC Press, New York, 1998.

[6] H. Y. Afeefy, J. F. Liebman, Computational Thermochemistry, ACS Symposium Series 677, American Chemical Society, Washington, DC, 1998, chapter 5 . 
[7] W. Thiel, Computational Thermochemistry, ACS Symposium Series 677, American Chemical Society, Washington, DC, 1998, chapter 8.

[8] Gaussian 09, Revision B.01, M. J. Frisch, G. W. Trucks, H. B. Schlegel, G. E. Scuseria, M. A. Robb, J. R. Cheeseman, G. Scalmani, V. Barone, B. Mennucci, G. A. Petersson, H. Nakatsuji, M. Caricato, X. Li, H. P. Hratchian, A. F. Izmaylov, J. Bloino, G. Zheng, J. L. Sonnenberg, M. Hada, M. Ehara, K. Toyota, R. Fukuda, J. Hasegawa, M. Ishida, T. Nakajima, Y. Honda, O. Kitao, H. Nakai, T. Vreven, J. A. Montgomery, Jr., J. E. Peralta, F. Ogliaro, M. Bearpark, J. J. Heyd, E. Brothers, K. N. Kudin, V. N. Staroverov, T. Keith, R. Kobayashi, J. Normand, K. Raghavachari, A. Rendell, J. C. Burant, S. S. Iyengar, J. Tomasi, M. Cossi, N. Rega, J. M. Millam, M. Klene, J. E. Knox, J. B. Cross,V. Bakken, C. Adamo, J. Jaramillo, R. Gomperts, R. E. Stratmann, O. Yazyev, A. J. Austin, R. Cammi, C. Pomelli, J. W. Ochterski, R. L. Martin, K. Morokuma, V. G. Zakrzewski, G. A. Voth, P. Salvador, J. J. Dannenberg, S. Dapprich, A. D. Daniels, Ö. Farkas, J. B. Foresman, J. V. Ortiz, J. Cioslowski, D. J. Fox, Gaussian Inc., Wallingford CT, 2010.

[9] J. W. Ochterski, Thermochemistry in Gaussian, Gaussian, Inc., 2000; url: http://www.gaussian.com/g_whitepap/thermo.htm.

[10] D. A. McQuarrie, J. D. Simon, Molecular Thermodynamics, University Science Books, Sausolito, CA, 1999.

[11] L. K. Nash, Elements of Statistical Thermodynamics, Addison Wesley, Reading, MA, 1968.

[12] M.-J. Crawford, T. M. Klapötke, F. A. Martin, C. Miró Sabaté, M. Rusan Chem. Asian J. 2011, 17, 1683-1695.

[13] G. N. Merrill, M. S. Gordon, J. Chem. Phys. 1999, 110, 6154-6157.

[14] J. A. Pople, A. P. Scott, M. W. Wong, L. Radom, Isr. J. Chem. 1993, 33, $345-350$.

[15] M. P. Andersson, P. Uvdal, J. Phys. Chem. A 2005, 109, 2937-2941.

[16] a) K. K. Irikura, R. D. Johnson, R. N. Kacker, J. Phys. Chem. A 2005, 109, $8430-8437$; b) H. Chermette, Coord. Chem. Rev. 1998, 178-180, 699721.

[17] R. S. Grev, C. L. Janssen, H. F. Schaefer, J. Chem. Phys. 1991, 95, 5128 5132.

[18] a) A. P. Scott, L. Radom, J. Phys. Chem. 1996, 100, 16502-16513; b) M Alecu, J. Zheng, Y. Zhao, D. G. Truhlar, J. Chem. Theory Comput. 2010, 6, 2872-2887

[19] G. I. Csonka, A. Ruzsinszky, J. P. Perdew, J. Phys. Chem. A 2005, 109, 6779-6789.

[20] K. K. Irikura, R. D. Johnson, R. N. Kacker, R. Kessel, J. Phys. Chem. 2009 130, 114102.

[21] R. D. Johnson, NIST Standard Reference Database 2011, 101, http:// cccbdb.nist.gov/.

[22] C. W. Bauschlicher, H. Partridge, J. Chem. Phys. 1995, 103, 1788-1791.

[23] M. W. Wong, Chem. Phys. Lett. 1996, 256, 391-399.

[24] Y. Tantirungrotechai, K. Phanasant, S. Roddecha, P. Surawatanawong, V. Sutthikhum, J. Limtrakul, THEOCHEM 2006, 760, 189-192.

[25] J. P. Merrick, D. Moran, L. Radom, J. Phys. Chem. A 2007, 111, $11683-$ 11700.

[26] S. G. Andrade, L. C. S. Gonçalves, F. E. Jorge, THEOCHEM 2008, 864, 20 25.

[27] A. Canal Neto, E. P. Muniz, R. Centoducatte, F. E. Jorge, THEOCHEM 2005, 718, 219-224.

[28] P. L. Barbieri, P. A. Fantin, F. E. Jorge, Mol. Phys. 2006, 104, 2945-2954.

[29] P. Politzer, P. Lane, M. C. Concha in Energetic Materials: Part 1: Decomposition, Crystal and Molecular Properties (Eds.: P. Politzer, J. S. Murray), Elsevier, Amsterdam, 2003, chapter 9.

[30] P. Politzer, Y. Ma, P. Lane, M. C. Concha, Int. J. Quantum Chem. 2005, $105,341-347$.

[31] B. M. Rice, S. V. Pai, J. Hare, Combust. Flame 1999, 118, 445-458.

[32] E. F. C. Byrd, B. M. Rice, J. Phys. Chem. A 2006, 110, 1005-1013.

[33] P. Politzer, J. S. Murray in Quantitative Treatments of Solute/Solvent In teractions: Theoretical and Computational Chemistry (Eds.: P. Politzer, J. S. Murray), Elsevier, Amsterdam, 1994.

[34] P. Politzer, J. S. Murray, THEOCHEM 1998, 425, 107-114.

[35] P. Politzer, J. S. Murray, Trends Chem. Phys. 1999, 7, 157-168.

[36] R. F. W. Bader, M. T. Carroll, J. R. Cheeseman, C. Chang, J. Am. Chem. Soc. 1987, 109, 7968-7979.

[37] P. Politzer, J. S. Murray, M. E. Grice, M. Desalvo, E. Miller, Mol. Phys. 1997, 91, 923-928.

[38] H. B. Schlegel, A. Skancke, J. Am. Chem. Soc. 1993, 115, 7465-7471.
[39] G. A. Petersson, D. K. Malick, W. G. Wilson, J. W. Ochterski, J. A. Montgomery, Jr., M. J. Frisch, J. Chem. Phys. 1998, 109, 10570-10579.

[40] P. Politzer, J. S. Murray, J. M. Seminario, P. Lane, M. E. Grice, M. C. Concha, THEOCHEM 2001, 573, 1-10.

[41] P. Politzer, P. Lane, M. C. Concha, J. Phys. Chem. A 2004, 108, 3493 3498.

[42] B. M. Rice, J. Hare, Thermochim. Acta 2002, 384, 377-391.

[43] E. F. C. Byrd, B. M. Rice, J. Phys. Chem. A 2009, 113, 5813-5813.

[44] E. F. C. Byrd, B. M. Rice, J. Phys. Chem. A 2009, 113, 345-352.

[45] A. G. Baboul, L. A. Curtiss, P. C. Redfern, K. Raghavachari, J. Chem. Phys. 1999, 110, $7650-7657$.

[46] L. A. Curtiss, K. Raghavachari, Theo. Chim. Acta 2002, 108, 61-70.

[47] G.-H. Tao, Y. Guo, Y.-H. Joo, B. Twamley, J. M. Shreeve, J. Mater. Chem. 2008, 18, 5524-5530.

[48] Y.-H. Joo, J. M. Shreeve, Org. Lett. 2008, 10, 4665-4667.

[49] Y. Zhang, Y. Guo, Y.-H. Joo, D. A. Parrish, J. M. Shreeve, Chem. Eur. J. 2010, 16, 10778-10784.

[50] Y.-H. Joo, H. Gao, D. A. Parrish, S. G. Cho, E. M. Goh, J. M. Shreeve, J. Mater. Chem. 2012, 22, 6123-6130.

[51] R. Wang, H. Gao, C. Ye, B. Twamley, J. M. Shreeve, Inorg. Chem. 2007, 46, $932-938$.

[52] R. Wang, Y. Guo, Z. Zeng, B. Twamley, J. M. Shreeve, Chem. Eur. J. 2009 , $15,2625-2634$

[53] C. Ye, H. Gao, J. M. Shreeve, J. Fluorine Chem. 2007, 128, 1410-1415.

[54] H. Gao, Y.-H. Joo, B. Twamley, Z. Zhou, J. M. Shreeve, Angew. Chem. Int. Ed. 2009, 48, 2792-2795; Angew. Chem. 2009, 121, 2830-2833.

[55] C. Ye, H. Gao, B. Twamley, J. M. Shreeve, New J. Chem. 2008, 32, 317 322

[56] H. Gao, C. Ye, R. W. Winter, G. L. Gard, M. E. Sitzmann, J. M. Shreeve, Eur. J. Inorg. Chem. 2006, 3221-3226.

[57] Y. Gao, C. Ye, B. Twamley, J. M. Shreeve, Chem. Eur. J. 2006, 12, $9010-$ 9018.

[58] Y. Guo, H. Gao, B. Twamley, J. M. Shreeve, Adv. Mater. 2007, 19, $2884-$ 2888.

[59] Z. Zeng, H. Gao, B. Twamley, J. M. Shreeve, J. Mater. Chem. 2007, 17, $3819-3826$.

[60] H. Gao, C. Ye, C. M. Piekarski, J. M. Shreeve, J. Phys. Chem. C 2007, 111 , $10718-10731$

[61] H. Gao, C. Ye, O. D. Gupta, J.-C. Xiao, M. A. Hiskey, B. Twamley, J. M. Shreeve, Chem. Eur. J. 2007, 13, 3853-3860.

[62] Z. Zeng, R. Wang, B. Twamley, D. A. Parrish, J. M. Shreeve, Chem. Mater. 2008, 20,6176-6182.

[63] Y. Huang, H. Gao, B. Twamley, J. M. Shreeve, Inorg. Chem. 2008, 16, $2560-2568$.

[64] L. He, G.-H. Tao, D. A. Parrish, J. M. Shreeve, Chem. Eur. J. 2010, 16, $5736-5743$.

[65] Y.-H. Joo, J. M. Shreeve, Angew. Chem. Int. Ed. 2009, 48, 564-567; Angew. Chem. 2009, 121, 572-575.

[66] Y.-H. Joo, J. M. Shreeve, Chem. Eur. J. 2009, 15, 3198-3203.

[67] Y.-H. Joo, B. Twamley, J. M. Shreeve, Chem. Eur. J. 2009, 15, 9097-9104.

[68] Y.-H. Joo, J. M. Shreeve, Inorg. Chem. 2009, 48, 8431-8438.

[69] Y.-H. Joo, J. M. Shreeve, J. Am. Chem. Soc. 2010, 132, $15081-15090$.

[70] V. Thottempudi, H. Gao, J. M. Shreeve, J. Am. Chem. Soc. 2011, 133, 6464-6471.

[71] V. Thottempudi, J. M. Shreeve, J. Am. Chem. Soc. 2011, 133, 19982 19992.

[72] T. M. Klapötke, K. Karaghiosoff, P. Mayer, A. Penger, J. M. Welch, Propellants Explos. Pyrotech. 2006, 31, 188-195.

[73] G. Geisberger, T. M. Klapötke, J. Stierstorfer, Eur. J. Inorg. Chem. 2007 $4743-4750$.

[74] T. M. Klapötke, C. Miró Sabaté, Z. Anorg. Allg. Chem. 2007, 633, 2671 2677.

[75] T. M. Klapötke, B. Krumm, F. X. Steemann, Propellants Explos. Pyrotech. 2009, 34, 13-23.

[76] M. Eberspächer, T. M. Klapötke, C. Miró Sabaté, Helv. Chim. Acta 2009, 92, 977-996.

[77] M. Göbel, T. M. Klapötke, Z. Anorg. Allg. Chem. 2007, 633, 1006-1017.

[78] T. M. Klapötke, F. X. Steemann, M. Sućeska, Propellants Explos. Pyrotech. 2008, 33, 213-218.

[79] J. Stierstorfer, T. M. Klapötke, A. Hammerl, R. D. Chapman, Z. Anorg. Allg. Chem. 2008, 634, $1051-1057$. 
[80] M.-J. Crawford, K. Karaghiosoff, T. M. Klapötke, F. A. Martin, Inorg. Chem. 2009, 48, $1731-1743$.

[81] T. M. Klapötke, P. Mayer, C. Miró Sabaté, J. M. Welch, N. Wiegand, Inorg. Chem. 2008, 47, 6014-6027.

[82] T. M. Klapötke, C. Miró Sabate, New J. Chem. 2009, 33, 1605-1617.

[83] T. M. Klapötke, C. Miró Sabaté, Z. Anorg. Allg. Chem. 2009, 635, 1812 1822.

[84] T. M. Klapötke, C. Miró Sabaté, A. Penger, M. Rusan, J. M. Welch, Eur. J. Inorg. Chem. 2009, 880-896.

[85] T. M. Klapötke, C. Miró Sabaté, Z. Anorg. Allg. Chem. 2010, 636, $163-$ 175.

[86] T. M. Klapötke, J. Stierstorfer, Phys. Chem. Chem. Phys. 2008, 10, $4340-$ 4346.

[87] N. Fischer, T. M. Klapötke, J. Stierstorfer, Z. Anorg. Allg. Chem. 2011, 637, $1273-1276$.

[88] T. M. Klapötke, F. A. Martin, J. Stierstorfer, Chem. Eur. J. 2012, 18, $1487-$ 1501.

[89] D. A. Dixon, D. Feller, K. O. Christe, W. W. Wilson, A. Vij, V. Vij, H. D. B. Jenkins, R. M. Olson, M. S. Gordon, J. Am. Chem. Soc. 2004, 126, $834-$ 843.

[90] T. E. Mallouk, G. L. Rosenthal, G. Mueller, R. Brusasco, N. Bartlett, Inorg. Chem. 1984, 23, 3167-3173.

[91] H. Donald, B. Jenkins, H. K. Roobottom, J. Passmore, L. Glasser, Inorg. Chem. 1999, 38, 3609-3620.

[92] H. Donald, B. Jenkins, D. Tudela, L. Glasser, Inorg. Chem. 2002, 41, $2364-2367$

[93] D. Tudela, M. Díaz, D. A. Alvaro, J. Ignacio, L. Seijo, V. K. Belsky, Organometallics 2001, 20, 654-662.

[94] A. D. Fortes, J. P. Brodholt, I. G. Wood, L. Vočadlo, H. D. B. Jenkins, J. Chem. Phys. 2001, 115, 7006-7014.

[95] A. Hammerl, T. M. Klapötke, H. Nöth, M. Warchhold, G. Holl, M. Kaiser, U. Ticmanis, Inorg. Chem. 2001, 40, 3570-3575.

[96] A. Vij, W. W. Wilson, V. Vij, F. S. Tham, J. A. Sheehy, K. O. Christe, J. Am. Chem. Soc. 2001, 123, 6308-6313.

[97] K. E. Gutowski, R. D. Roger, D. A. Dixon, J. Phys. Chem. B 2007, 111, $4788-4800$.

[98] Y. Marcus, H. Donald, B. Jenkins, L. Glasser, Dalton Trans. 2002, 111, $3795-3798$.

[99] H. Donald, B. Jenkins, L. Glasser, T. M. Klapötke, M.-J. Crawford, K. K. Bhasin, J. Lee, G. J. Schrobilgen, L. S. Sunderlin, J. F. Liebman, Inorg. Chem. 2004, 43, 6238-6248.

[100] L. Qiu, H. Xiao, X. Gong, X. Ju, W. Zhu, J. Hazard. Mater. 2007, 141, $280-288$.

[101] B. M. Rice, J. J. Hare, E. F. C. Byrd, J. Phys. Chem. A 2007, 111, $10874-$ 10879.

[102] V. Forquet, C. Miró Sabaté, G. Jacob, Y. Guelou, H. Delalu, C. Darwich Chem. Asian J., 2015, 10, 1668-1675.

[103] M. Göbel, T. M. Klapötke, P. Mayer, Z. Anorg. Allg. Chem. 2006, 632, $1043-1050$
[104] a) J. Bernstein, R. E. Davis, L. Shimoni, N. Chang, Angew. Chem. Int. Ed. Engl. 1995, 34, 1555-1573; Angew. Chem. 1995, 107, 1689-1708; b) RPLUTO computer program, v5.26, CCDC, 2014.

[105] H. H. Michels, J. A. Montgomery, Jr., K. O. Christe, D. A. Dixon, J. Phys. Chem. 1995, 99, 187-194.

[106] O. Kwon, M. L. McKee in Energetic Materials: Part 1: Decomposition, Crystal and Molecular Properties (Eds.: P. Politzer, J. S. Murray), Elsevier, Amsterdam, 2003.

[107] M. E. C. Biffin, J. Miller, D. B. Paul, The Chemistry of the Azido Group, Interscience, New York, 1971.

[108] J. W. Ochterski, G. A. Petersson, J. A. Montgomery, Jr., J. Chem. Phys. 1996, 104, 2598-2619.

[109] J. A. Montgomery, Jr., M. J. Frisch, J. W. Ochterski, G. A. Petersson, J. Chem. Phys. 1999, 110, 2822-2827.

[110] M. Rahm, T. Brinck, Chem. Eur. J. 2010, 16, 6590-6600.

[111] P. J. Linstromm, W. G. Mallard, NIST Chemistry WebBook, 69, National Institute of Standards and Technology, Gaithersburg MD, 20899. URL: http://webbook.nist.gov.

[112] CRCnetBASE, Handbook of Chemistry \& Physics Online, CRC Press, Boca Raton; url: http://www.hbcpnetbase.com/.

[113] M. W. Chase, Jr., J. Phys. Chem. Ref. Data 1998, 9, 1-1951.

[114] H. D. B. Jenkins, Mol. Phys. 1976, 32, $231-236$.

[115] D. D. Wagman, W. H. Evans, V. B. Parker, R. H. Schumm, I. Halow, S. M. Bailey, K. L. Churney, R. L. Nuttall, The NBS Tables of Chemical Thermodynamic properties. Selected values for inorganic and C1 C2 organic substance in SI units in J. Phys. Chem. Ref. Data 1982, Supplement 2, 1 407.

[116] T. M. Donovan, C. H. Shomate, W. R. McBride, J. Phys. Chem. B 1960, 64, $281-282$.

[117] K. E. Gutowski, R. D. Rogers, D. A. Dixon, J. Phys. Chem. A 2006, 110, $11890-11897$

[118] E. A. Miroshnichenko, Y. A. Lebedev, S. A. Shevelev, V. I. Gulevskaya, A. A. Fainzil'berg, A. Y. Apin, Russ. J. Phys. Chem. 1967, 41, 783-785.

[119] a) B. J. McBride, S. Gordon, Interim Report, NASA SP-273, 1976; b) B. J. McBride, S. Gordon, Interim Report, NASA TM-100785, 1988; c) B. J. McBride, S. Gordon, Interim Report, NASA RP-1311, 1994.

[120] CrysAlisPro, Agilent Technologies, v. 1.171.34.49 (release 20-01-2011 CrysAlis171.NET) (compiled Jan 20, 2011, 15:58:25).

[121] R. C. Clark, J. S. Reid, Acta. Crystallogr. A 1995, 51, 887-897.

[122] A. Altomare, M. C. Burla, M. Camalli, G. L. Cascarano, C. Giacovazzo, A Guagliardi, A. Grazia, G. Moliterni, G. Polidori, R. Spagna, J. Appl. Crystallogr. 1999, 32, 115-119.

[123] P. W. Betteridge, J. R. Carruthers, R. I. Cooper, K. Prout, D. J. Watkin, J. Appl. Crystallogr. 2003, 36, 1487.

[124] K. Brandenburg, Diamond v. $3.2 \mathrm{~g}$ (version created: Feb 8, 2011, 16:12:07), Crystal Impact GbR, Bonn (Germany). 